Check for updates

Cite this: Dalton Trans., 2022, 51, 361

\title{
Physical properties of $\{\mathrm{Ti}, \mathrm{Zr}, \mathrm{Hf}\}_{2} \mathrm{Ni}_{2} \mathrm{Sn}$ compounds $\uparrow$
}

\author{
V. V. Romaka, ta,b G. Rogl, (D) a V. Buršíková, ${ }^{\mathrm{c}} \mathrm{J}$. Buršík, (D) ${ }^{\mathrm{d}} \mathrm{H}$. Michor, (D) e
}

A. Grytsiv, (D) ${ }^{a}$ E. Bauer, (DD ${ }^{e}$ G. Giester $\left(\mathbb{D}^{f}\right.$ and P. Rogl (D) *a

Physical properties, i.e. electrical resistivity (4.2-800 K), Seebeck coefficient (300-800 K), specific heat (2-110 K), Vickers hardness and elastic moduli (RT), have been defined for single-phase compounds with slightly nonstoichiometric compositions: $\mathrm{Ti}_{2.13} \mathrm{Ni}_{2} \mathrm{Sn}_{0.87}, \mathrm{Zr}_{2.025} \mathrm{Ni}_{2} \mathrm{Sn}_{0.975}$, and $\mathrm{Hf}_{2.055} \mathrm{Ni}_{2} \mathrm{Sn}_{0.945}$. From $\mathrm{X}$-ray single crystal and TEM analyses, $\mathrm{Ti}_{2+x} \mathrm{Ni}_{2} \mathrm{Sn}_{1-x}, x \sim 0.13(1)$, is isotypic with the $\mathrm{U}_{2} \mathrm{Pt}_{2} \mathrm{Sn}$-type (space group $\mathrm{P}_{2} / \mathrm{mnm}$, ternary ordered version of the $\mathrm{Zr}_{3} \mathrm{Al}_{2}$-type), also adopted by the homologous compounds with $\mathrm{Zr}$ and $\mathrm{Hf}$. For all three polycrystalline compounds (relative densities $>95 \%$ ) the electrical resistivity of the samples is metallic-like with dominant scattering from static defects mainly conditioned by off-stoichiometry. Analyses of the specific heat curves $C_{p} v s . T$ and $C_{p} / T$ vs. $T^{2}$ reveal Sommerfeld coefficients of $\gamma_{\mathrm{Ti}_{2} \mathrm{Ni}_{2} \mathrm{Sn}}=14.3(3) \mathrm{mJ} \mathrm{mol}{ }^{-1} \mathrm{~K}^{-2}, \gamma_{\mathrm{Zr}_{2} \mathrm{Ni}_{2} \mathrm{Sn}}=10(1) \mathrm{mJ} \mathrm{mol}^{-1} \mathrm{~K}^{-2}, \gamma_{\mathrm{Hf}_{2} \mathrm{Ni}_{2} \mathrm{Sn}}=9.1(5) \mathrm{mJ} \mathrm{mol}^{-1} \mathrm{~K}^{-2}$ and low-temperature Debye-temperatures: $\theta_{D}^{\mathrm{LT}}=373(7) \mathrm{K}, 357(14) \mathrm{K}$ and $318(10) \mathrm{K}$. Einstein temperatures were in the range of 130-155 K. Rather low Seebeck coefficients $\left(<15 \mu \mathrm{V} \mathrm{K}{ }^{-1}\right.$ ), power factors ( $\mathrm{pf}<0.07 \mathrm{~mW}$ $\mathrm{mK}^{-2}$ ) and an estimated thermal conductivity of $\lambda<148 \mathrm{~mW} \mathrm{~cm}^{-1} \mathrm{~K}^{-1}$ yield thermoelectric figures of merit ZT $<0.007$ at $\sim 800 \mathrm{~K}$. Whereas for polycrystalline $\mathrm{Zr}_{2} \mathrm{Ni}_{2} \mathrm{Sn}$ elastic properties were determined by resonant ultrasound spectroscopy (RUS): $E=171 \mathrm{GPa}, \nu=0.31, \mathrm{G}=65.5 \mathrm{GPa}$, and $B=147 \mathrm{GPa}$, the accelerated mechanical property mapping (XPM) mode was used to map the hardness and elastic moduli of $\mathrm{T}_{2} \mathrm{Ni}_{2} \mathrm{Sn}$. Above $180 \mathrm{~K}, \mathrm{Zr}_{2} \mathrm{Ni}_{2} \mathrm{Sn}$ reveals a quasi-linear expansion with CTE $=15.4 \times 10^{-6} \mathrm{~K}^{-1}$. The calcu-

Received 20th September 2021, Accepted 4th November 2021

DOI: $10.1039 / \mathrm{d} 1 \mathrm{dt} 03198 \mathrm{~h}$

rsc.li/dalton lated density of states is similar for all three compounds and confirms a metallic type of conductivity. The isosurface of elf shows a spherical shape for $\mathrm{Ti} / \mathrm{Zr} / \mathrm{Hf}$ atoms and indicates their ionic character, while the $\left[\mathrm{Ni}_{2} \mathrm{Sn}\right]^{n-}$ sublattice reflects localizations around the $\mathrm{Ni}$ and $\mathrm{Sn}$ atoms with a large somewhat diffuse charge density between the closest $\mathrm{Ni}$ atoms.

\section{Introduction}

Since the discovery of a band gap in $\{\mathrm{Ti}, \mathrm{Zr}, \mathrm{Hf}\} \mathrm{NiSn}$ compounds and consequently the high thermoelectric potential of these half-Heusler type alloys, the three ternary systems $\{\mathrm{Ti}, \mathrm{Zr}, \mathrm{Hf}\}-\mathrm{Ni}-\mathrm{Sn}$ have moved into the focus of thermoelectric research. For the metallurgical optimization of the thermoelec-

\footnotetext{
${ }^{a}$ Institute of Materials Chemistry, Universität Wien, Währingerstr. 42, A-1090 Wien, Austria. E-mail: peter.franz.rogl@univie.ac.at

${ }^{b}$ Leibniz Institute for Solid State and Materials Research Dresden (IFW Dresden), Helmholtzstr. 20, D-01069 Dresden, Germany

'Institute of Physical Electronics, Masaryk University, Kotlářská 2, 61137 Brno, Czech Republic

${ }^{d}$ Institute of Physics of Materials, Czech Academy of Sciences, Žižkova 22, 61662 Brno, Czech Republic

${ }^{e}$ Institute of Solid State Physics, TU Wien, Wiedner Hauptstr. 8-10, A-1040 Wien, Austria

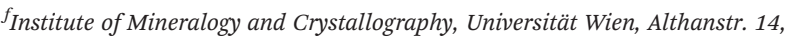
A-1090 Wien, Austria

$\dagger$ Electronic supplementary information (ESI) available. See DOI: 10.1039/ d1dt03198h

\$Present address: Chair of Inorganic Chemistry, TU Dresden, Bergstrasse 66, 01069 Dresden, Germany.
}

tric figure of merit ZT of the half-Heusler alloys, a thorough investigation of the ternary systems was necessary. Whereas for $\mathrm{Ti}-\mathrm{Ni}-\mathrm{Sn}$ and $\mathrm{Zr}-\mathrm{Ni}-\mathrm{Sn}$ phase relations were derived from $600{ }^{\circ} \mathrm{C}$ to the liquidus surface, crystal structures and homogeneity regions of all ternary compounds were assembled and thermodynamic CALPHAD calculations were based on these experimental findings,,${ }^{1,2}$ the only phase diagram sources available for the $\mathrm{Hf}-\mathrm{Ni}-\mathrm{Sn}$ system are an isothermal section at $600{ }^{\circ} \mathrm{C}$ (ref. 3) and a thermodynamic CALPHAD estimation. ${ }^{4}$ The high significance of the phase diagram studies is documented in the high thermoelectric performance of $\{\mathrm{Ti}, \mathrm{Zr}, \mathrm{Hf}\}$ NiSn grades exploiting the grain refining effects of spinodal decomposition combined with precipitation mechanisms from a supersaturated temperature dependent solid solution, which altogether led to $\mathrm{ZT}=1.5$ for $\{\mathrm{Ti}, \mathrm{Zr}, \mathrm{Hf}\} \mathrm{NiSn}$ and $\mathrm{ZT}=1.2$ for Hf-free grades $\{\mathrm{Ti}, \mathrm{Zr}\} \mathrm{NiSn}^{5,6}$ It is interesting to note that in all three ternary systems $\{\mathrm{Ti}, \mathrm{Zr}, \mathrm{Hf}\}-\mathrm{Ni}-\mathrm{Sn}$, we observe a two-phase equilibrium: $\{\mathrm{Ti}, \mathrm{Zr}, \mathrm{Hf}\} \mathrm{Ni}_{2} \mathrm{Sn}$ (Heusler phase) $+\{\mathrm{Ti}, \mathrm{Zr}$, $\mathrm{Hf}_{2} \mathrm{Ni}_{2} \mathrm{Sn}$ and for $\mathrm{Zr}-\mathrm{Ni}-\mathrm{Sn}$ also a 3-phase equilibrium: ZrNiSn (half Heusler phase) $+\mathrm{ZrNi}_{2} \mathrm{Sn}$ (Heusler phase) + $\mathrm{Zr}_{2} \mathrm{Ni}_{2} \mathrm{Sn}$. Although the latter phase has been characterized with respect to the crystal structure, little is known about the 
physical properties of this phase. Whilst the crystal structure of $\mathrm{Zr}_{2} \mathrm{Ni}_{2} \mathrm{Sn}$ and $\mathrm{Hf}_{2} \mathrm{Ni}_{2} \mathrm{Sn}$ has been determined from X-ray single crystal studies ${ }^{7,8}$ to derive as an ordered $\mathrm{Zr}_{3} \mathrm{Al}_{2}$-type (space group $\mathrm{P}_{2} / \mathrm{mnm}$ ) from the simpler subcell with the $\mathrm{Mo}_{2} \mathrm{FeB}_{2}$-type (space group $\mathrm{P} 4 / \mathrm{mbm}$; ordered $\mathrm{U}_{3} \mathrm{Si}_{2}$-type), only $\mathrm{X}$-ray powder data have been available for $\mathrm{Ti}_{2} \mathrm{Ni}_{2} \mathrm{Sn}$ claiming isotypism with the $\mathrm{U}_{2} \mathrm{Pt}_{2} \mathrm{Sn}$-type (ternary ordered version of the $\mathrm{Zr}_{3} \mathrm{Al}_{2}$-type). ${ }^{1,9} \mathrm{R}$. Pöttgen et al. ${ }^{7}$ and Zumdick et al. ${ }^{8}$ furthermore reported on the electrical resistivity and magnetic susceptibility of both $\mathrm{Zr}_{2} \mathrm{Ni}_{2} \mathrm{Sn}$ and $\mathrm{Hf}_{2} \mathrm{Ni}_{2} \mathrm{Sn}(4.2$ to $300 \mathrm{~K})$, however, without quantification of the measured data. The ${ }^{119} \mathrm{Sn}$ Mössbauer data were interpreted for $\mathrm{Zr}_{2} \mathrm{Ni}_{2} \mathrm{Sn}$ and $\mathrm{Hf}_{2} \mathrm{Ni}_{2} \mathrm{Sn}{ }^{8}$ On checking the Internet for elastic properties we came across the data for $\mathrm{Hf}_{2} \mathrm{Ni}_{2} \mathrm{Sn}$ produced using the program ELATE, ${ }^{10}$ which unfortunately used the outdated crystal data set with the $\mathrm{Mo}_{2} \mathrm{FeB}_{2}$-type subcell.

The present paper with respect to the absence of reliable X-ray single crystal structure data for $\mathrm{Ti}_{2} \mathrm{Ni}_{2} \mathrm{Sn}$ attempts (a) to provide X-ray single crystal and transmission electron microscopy (TEM) data on the structure of $\mathrm{Ti}_{2} \mathrm{Ni}_{2} \mathrm{Sn}$ and (b) physical property data for the detailed characterization of the three $\mathrm{T}_{2} \mathrm{Ni}_{2} \mathrm{Sn}$ phases ( $\left.\mathrm{T}=\mathrm{Ti}, \mathrm{Zr}, \mathrm{Hf}\right)$ and (c) to back the experimentally derived properties by DFT eDOS data and (d) electron density data to shed light on the chemical bonding.

\section{Experimental}

Pure elements in the form of Van Arkel Ti-ingot (99.99 mass\%), Zr-rod (99.8 mass\%), Hf-pieces (99.8 mass\%), Ni-rod (99.95 mass\%), and Sn-shot or bars (99.9 mass\%) were used as starting materials to prepare alloys with various compositions close to $\mathrm{T}_{2} \mathrm{Ni}_{2} \mathrm{Sn}$. Details on sample preparation, ball-milling and hot-pressing conditions are given in ref. 5 . Due to the non-congruent melting behavior and the homogeneity region of the $\mathrm{T}_{2} \mathrm{Ni}_{2} \mathrm{Sn}$ phases (extending in the direction of $\mathrm{T}_{2+x} \mathrm{Ni}_{2} \mathrm{Sn}_{1-x}$ ) a large number of samples (about $10 \mathrm{~g}$ ) for physical property measurements were prepared from the nominal composition $\mathrm{T}_{42} \mathrm{Ni}_{40} \mathrm{Sn}_{18}$ by argon arc melting, subsequent ball-milling and densification via hot pressing in graphite dies. For the Ti-samples an additional annealing step was added for 3 days at $1000{ }^{\circ} \mathrm{C}$; the samples were sealed in evacuated quartz vials, which were backfilled to $300 \mathrm{mbar} \mathrm{Ar}$ (the samples wrapped in protective Mo-foil). From the cylinders obtained $(\varnothing=10 \mathrm{~mm}, h \sim 8 \mathrm{~mm}$ ), specimens were cut with a diamond saw to the specification of the corresponding measurement technique.

The microstructure and chemical composition of the alloys were analyzed with a SEM (scanning electron microscope: Zeiss Supra 55 VP equipped with an EDX detector operated at $20 \mathrm{kV}$ ) on the sample surfaces that were ground on SiC papers and polished with $\mathrm{Al}_{2} \mathrm{O}_{3}$ powders (down to $0.3 \mu \mathrm{m}$ ) via standard procedures. Quantitative evaluation of the compositions was performed with the INCA - software. ${ }^{11}$

$\mathrm{X}$-ray powder diffraction profiles were collected from a HUBER-Guinier image plate with monochromated $\mathrm{CuK}_{\alpha 1}$-radi- ation $(\lambda=0.154056 \mathrm{~nm})$. For Rietveld refinements the FULLPROF program was applied. ${ }^{12}$ Precise lattice parameters were calculated by least-squares fits with the program STRUKTUR $^{13}$ to the indexed $\theta$-values employing $99.9999 \% \mathrm{Ge}$ as the internal standard $\left(a_{\mathrm{Ge}}=0.5657906 \mathrm{~nm}\right)$.

A small and rather spherical specimen $\left(\sim 35 \times 40 \times 50 \mu \mathrm{m}^{3}\right)$ suitable for the X-ray single crystal structure analysis of $\mathrm{Ti}_{2} \mathrm{Ni}_{2} \mathrm{Sn}$ was isolated by mechanical fragmentation of an arcmelted alloy $\mathrm{Ti}_{44} \mathrm{Ni}_{40} \mathrm{Sn}_{16}$. After inspection with an AXS D8GADDS texture goniometer, which assured the high crystal quality, unit cell dimensions and Laue symmetry of the single crystal specimens, X-ray intensity data were collected at room temperature on a four-circle APEX II diffractometer equipped with a CCD area detector and an Incoatec Microfocus Source $\mathrm{I} \mu \mathrm{S}\left(30 \mathrm{~W}\right.$, multilayer mirror, $\mathrm{Mo}^{-\mathrm{K}_{\alpha}} ; \lambda=0.071069 \mathrm{~nm}$; detector distance of $3 \mathrm{~cm}$; full sphere; $2^{\circ}<2 \theta<70^{\circ}$ ). Besides the general treatment of absorption effects using the multi-scan technique (SADABS; redundancy of integrated reflections $>9$ ) ${ }^{14}$ no individual absorption correction was necessary because of the rather regular crystal shape and small dimensions of the investigated specimens. The crystal structure was solved by applying direct methods (program SHELXS-97) and refined against $F^{2}$ (program SHELXL-97-2) with the program OSCAIL. ${ }^{15}$ Finally, the crystal structure was standardized with the program STRUCTURE TIDY. ${ }^{16}$

Thin lamellae (lateral dimensions about $10 \times 7 \mu \mathrm{m}^{2}$ ) for the TEM study were prepared from the as cast alloy $\mathrm{Ti}_{44} \mathrm{Ni}_{40} \mathrm{Sn}_{16}$ using a focused ion beam (FIB) technique with a TESCAN LYRA 3 XMU FEG/SEM $\times$ FIB scanning electron microscope. A JEOL JEM-2100F transmission electron microscope (TEM) with FEG operated at $200 \mathrm{kV}$ was employed to get information about the crystal symmetry and lattice parameters of selected phases.

The measured density, $d_{\mathrm{A}}$, was derived from Archimedes' principle on the hot-pressed cylinders in distilled water. X-raydensity $d_{\mathrm{x}}=M Z / V L$ was calculated from $Z$ as the number of formula units within the unit cell, $M$ as the molar mass in $[\mathrm{g}$ $\left.\mathrm{mol}^{-1}\right], V$ as the volume and $L$ as Loschmidt's number. The relative density, $d_{\text {rel }}=\left(d_{\mathrm{A}} / d_{\mathrm{X}}\right) \times 100$.

The electrical resistivity in the range from 4.2 to $300 \mathrm{~K}$ was measured on cuboids $\left(8 \times 2 \times 2 \mathrm{~mm}^{3}\right)$ using a conventional ${ }^{4} \mathrm{He}$ cryostat via an a.c. four-point technique employing a Lake Shore Resistance Bridge 370 AC. The temperature of the sample was determined by using Ge and Pt100 resistive sensors in the temperature ranges $T<35 \mathrm{~K}$ and $T>35 \mathrm{~K}$, respectively. Above room temperature the electrical resistivity, $\rho$, and the Seebeck coefficient, $S$, were measured simultaneously with a ZEM-3 equipment (ULVAC-Riko, Japan). The error for both resistivity measurements and the Seebeck coefficient is $3 \%$. The specific heat of the samples with masses of 2.3 to $3.7 \mathrm{~g}$ was measured with a homemade calorimeter employing an adiabatic step heating method at temperatures from 2 to $110 \mathrm{~K}$.

The mechanical properties of the $\mathrm{T}_{2} \mathrm{Ni}_{2} \mathrm{Sn}$ compounds were measured by means of a Hysitron TI950 triboindenter with a maximum indentation load of $10 \mathrm{mN}$. Instead of standard qua- 
sistatic nanoindentation the accelerated mechanical property mapping mode $(\mathrm{XPM}$ ) uses a large number (up to $20 \times 20$ ) of indents on a surface area of $60 \times 60 \mu \mathrm{m}^{2}$ to map the local indentation response of the tested materials. The XPM mode allows one to obtain hardness and elastic modulus maps with high spatial resolution and low acquisition times. Compared to the most often used quasistatic indentation the XPM measuring method is substantially faster: the time necessary to perform one indent is more than one order of magnitude shorter. Faster measurements reduce the possible effects of thermal drift. Several maps were established using a Berkovich-type diamond indenter with a tip diameter of $\sim 50 \mathrm{~nm}$. Indenter tip calibration was performed on a certified fused silica sample (Bruker) exhibiting reduced modulus $E_{\mathrm{r}}=$ $(69.7 \pm 0.9) \mathrm{GPa}$, Poisson ratio $\nu=0.16$, and indentation hardness $H_{\mathrm{IT}}=(9.2 \pm 0.7) \mathrm{GPa}$. At least 100 indentation tests were carried out on the standard at different indentation depths in the load range from $100 \mu \mathrm{N}$ to $10 \mathrm{mN}$.

For $\mathrm{Zr}_{2} \mathrm{Ni}_{2} \mathrm{Sn}$ resonant ultrasound spectroscopy (RUS), ${ }^{17}$ was employed to derive elastic properties, Young's modulus, $E$, and Poisson ratio, $\nu$, via the eigenfrequencies of the sample (cube of $2 \times 2 \times 2 \mathrm{~mm}^{3}$ ) and the knowledge of the sample mass and dimensions (for details see ref. 18-20). For a fine-grained polycrystalline matrix, the bulk modulus $B$, the shear modulus $G$ and the elastic constant $C_{11}$ are obtained from relation (1).

$$
B=\frac{E}{3(1-2 \nu)}, \quad G=\frac{E}{2(\nu+1)} \quad \text { and } \quad C_{11}=3 \mathrm{~B}-\frac{6 B \nu}{1+\nu}
$$

The accuracy of the measurement technique depends on the quality (density, perfect shape) of the samples. $C_{12}$, the modulus for dilation on compression, can be calculated from eqn (2)

$$
G=\left(C_{11}-C_{12}\right) / 2 .
$$

Isotropic compounds are suitable for determining $\theta_{\mathrm{D}}$ from the sound velocity, using Anderson's eqn (3): ${ }^{21}$

$$
\theta_{\mathrm{D}}=\frac{h}{k_{\mathrm{B}}}\left(\frac{3 n L d_{\mathrm{A}}}{4 M \pi}\right)^{1 / 3} v_{\mathrm{m}}
$$

where $h$ is Planck's constant, $k_{\mathrm{B}}$ is Boltzmann's constant, $L$ is Loschmidt's number, $d_{\mathrm{A}}$ is the density, $M$ is the molecular weight, and $n$ is the number of atoms in the asymmetric unit cell. The mean sound velocity $v_{\mathrm{m}}$ follows from eqn (4)

$$
\begin{aligned}
v_{\mathrm{m}} & =\left[\frac{1}{3}\left(\frac{2}{v_{\mathrm{T}}^{3}}+\frac{1}{v_{L}^{3}}\right)\right]^{-1 / 3} \text { with } v_{\mathrm{L}}=\left(\frac{3 B+4 G}{3 d_{\mathrm{A}}}\right)^{1 / 2} \text { and } \\
v_{\mathrm{T}} & =\left(\frac{G}{d_{\mathrm{A}}}\right)^{1 / 2},
\end{aligned}
$$

where $v_{\mathrm{L}}$ and $v_{\mathrm{T}}$ are the longitudinal and transversal sound velocities, respectively. ${ }^{22}$

The thermal expansion from 4.2 to $300 \mathrm{~K}$ was measured with a miniature capacitance dilatometer using the tilted plate principle on the cubes used for RUS (for details see ref. 23-25).

DFT calculations were carried out using the Elk v4.3.06 package $^{26}$ - an all-electron full-potential linearized augmented-plane wave (FP-LAPW) code with the Perdew-BurkeEnzerhoff exchange-correlation functional in generalized gradient approximation (GGA). ${ }^{27}$ The $k$-point mesh was determined automatically based on a sphere with a given radius and resulted in a total of $196 k$-points. The appropriate values of the muffin-tin radii were selected automatically at the initial stage of the calculations. The $R_{\min }(\mathrm{MT}) \times\{|G+k|\}$ value was set to 8 , where $R_{\min }(\mathrm{MT})$ is the minimum muffin-tin radius used in the system to keep a reasonable balance between the accuracy and required time of calculations. The manual optimization of the lattice parameters was performed by fitting the universal equation of state. ${ }^{28}$ The enthalpy of formation $\left(\Delta H_{\mathrm{f}}\right)$ at $T=0 \mathrm{~K}$ was calculated using the total energies at the ground state of the corresponding constituents and compounds studied. The distribution of the total and partial densities of states (DOS) was calculated by a tri-linear method using a 2000 $k$-point grid for integrating functions in the Brillouin zone and 1000 energy points in the DOS plot. The interstitial DOS is included in the total DOS distribution, while the partial DOS for each atom type was obtained only within the volume of the appropriate muffin-tin sphere. The distribution of the charge density $(\rho)$ was calculated by using an $80 \times 80 \times 80$ point grid and plotted by the VESTA software package. ${ }^{29}$

\section{Results and discussion}

\subsection{Crystal structures of the $\left\{\mathrm{Ti}, \mathrm{Zr}, \mathrm{Hf}_{2}\right\}_{2} \mathrm{Ni}_{2} \mathrm{Sn}$ compounds}

Whereas the crystal structures of $\mathrm{Zr}_{2} \mathrm{Ni}_{2} \mathrm{Sn}$ and $\mathrm{Hf}_{2} \mathrm{Ni}_{2} \mathrm{Sn}$ have been elucidated from detailed single crystal X-ray data ${ }^{7,8}$ to be isotypic with the ordered $\mathrm{Zr}_{3} \mathrm{Al}_{2}$-type (space group $\mathrm{P4}_{2} / \mathrm{mnm}$; structures listed as the $\mathrm{U}_{2} \mathrm{Pt}_{2} \mathrm{Sn}$-type in Pearson's Crystal Data Base ${ }^{30}$ ), the corresponding crystal structure data for $\mathrm{Ti}_{2} \mathrm{Ni}_{2} \mathrm{Sn}$ are hitherto only available from X-ray powder data. For $\mathrm{Zr}_{2} \mathrm{Ni}_{2} \mathrm{Sn}$ and $\mathrm{Hf}_{2} \mathrm{Ni}_{2} \mathrm{Sn}$ the ordered $\mathrm{Zr}_{3} \mathrm{Al}_{2}$-type $\left(\mathrm{U}_{2} \mathrm{Pt}_{2} \mathrm{Sn}\right.$-type $)$ suffices to describe weak but well visible superstructure reflections, ${ }^{7,8}$ rendering older descriptions of the structure of $\mathrm{Zr}_{2} \mathrm{Ni}_{2} \mathrm{Sn}$ obsolete, which inferred the smaller $\mathrm{Mo}_{2} \mathrm{FeB}_{2}$-type (ordered $\mathrm{U}_{3} \mathrm{Si}_{2}$-type, intergrowth of CsCl-type and $\mathrm{AlB}_{2}$-type structural units ${ }^{31}$ ). From these analyses ${ }^{7,8}$ it is obvious that the ordered $\mathrm{Zr}_{3} \mathrm{Al}_{2}$-type is an $(a=b, 2 c)$ superstructure of the ordered $\mathrm{U}_{3} \mathrm{Si}_{2}$-type (space group $P 4 / \mathrm{mbm}$ ) in a group-subgroup relation relaxing the $z$-parameters of the Ni-atoms. Our recent phase diagram analysis of the system $\mathrm{Zr}-\mathrm{Ni}-\mathrm{Sn}^{2}$ revealed an incongruent formation of $\mathrm{Zr}_{2+x} \mathrm{Ni}_{2} \mathrm{Sn}_{1-x}$ from a pseudo-binary peritectic reaction: $\mathrm{L}+\mathrm{Zr}_{5} \mathrm{NiSn}_{3} \leftrightarrow \mathrm{Zr}_{2} \mathrm{Ni}_{2} \mathrm{Sn}$ at $1406{ }^{\circ} \mathrm{C}$. At an almost constant Ni-content ( $\sim 40$ at\%) a small homogeneity region extends towards lower Sn-contents: $\mathrm{Zr}_{2+x} \mathrm{Ni}_{2} \mathrm{Sn}_{1-x}$. Therefore the nominal composition for the single phase material was placed at a slightly non-stoichiometric composition $\mathrm{Zr}_{42} \mathrm{Ni}_{40} \mathrm{Sn}_{18}$ (in at\%). After hot-pressing the crushed arc melted buttons, metallographic (SEM) inspection arrived at a 
practically homogeneous material for which a Rietveld refinement confirmed the structure type of $\mathrm{U}_{2} \mathrm{Pt}_{2} \mathrm{Sn}\left(R_{\mathrm{F}}=0.034\right)$ with only a minute amount of 1 vol\% of $\mathrm{ZrNi}_{2} \mathrm{Sn}$ (Heusler type). For details of the Rietveld refinement of $\mathrm{Zr}_{2+x} \mathrm{Ni}_{2} \mathrm{Sn}_{1-x}(x=0.025$, derived from SEM-EDX) see Fig. S1 in the ESI. $\dagger$ The situation is quite similar for isotypic $\mathrm{Hf}_{2+x} \mathrm{Ni}_{2} \mathrm{Sn}_{1-x}$ : Rietveld refinement results for a practically single-phase sample at $x=0.055$ (derived from SEM-EDX) are summarized in Fig. S2 in the ESI. $\dagger$ For the Hf-Ni-Sn system neither a reliable liquidussolidus surface nor a SEM-EDX defined isothermal section is reported yet.

The light homologue $\mathrm{Ti}_{2+x} \mathrm{Ni}_{2} \mathrm{Sn}_{1-x}$ was found to form in a ternary peritectic reaction, $\mathrm{L}+\mathrm{Ti}_{5} \mathrm{NiSn}_{3}+\mathrm{TiNi}_{2} \mathrm{Sn} \leftrightarrow \mathrm{Ti}_{2} \mathrm{Ni}_{2} \mathrm{Sn}$ at $1151{ }^{\circ} \mathrm{C},{ }^{1}$ with a rather small field of primary crystallization; these two facts may explain why so far no single crystal was obtained in crystal structure analysis. X-ray powder diffraction data, however, have claimed isotypism with the $\mathrm{U}_{2} \mathrm{Pt}_{2} \mathrm{Sn}$ type. $^{1,9}$

The Rietveld refinement for $\mathrm{Ti}_{42} \mathrm{Ni}_{40} \mathrm{Sn}_{18}$ (nominal composition in at $\%$ of an arc melted, ball-milled and hot-pressed sample; see Fig. 1) indicated the $\mathrm{U}_{2} \mathrm{Pt}_{2} \mathrm{Sn}$-type structure besides a small amount of the $\mathrm{TiNi}_{2} \mathrm{Sn}$-Heusler phase. It should be mentioned that a test with the $\mathrm{Mo}_{2} \mathrm{FeB}_{2}$-type could not satisfactorily describe the X-ray powder intensities. A small single crystal suitable for X-ray structural analysis was isolated by the mechanical fragmentation of an arc-melted alloy $\mathrm{Ti}_{44} \mathrm{Ni}_{40} \mathrm{Sn}_{16}$. A full structural analysis in the space group $P 4_{2} /$ $m n m$ of the highest symmetry arrived at $R_{\mathrm{F}}{ }^{2}=0.0082$ with a residual electron density as low as $0.40 \mathrm{e}^{-} \AA^{-3}$ confirming the ordered $\mathrm{Zr}_{3} \mathrm{Al}_{2}$-type $\left(\mathrm{U}_{2} \mathrm{Pt}_{2} \mathrm{Sn}\right.$-type) and isotypism with $\mathrm{Zr}$ and Hf homologues (crystallographic details are summarized in Table 1).

It should be noted that the composition of the single crystal from refinement $\mathrm{Ti}_{2.13} \mathrm{Ni}_{2} \mathrm{Sn}_{0.87}\left(\equiv \mathrm{Ti}_{42.6} \mathrm{Ni}_{40} \mathrm{Sn}_{17.4}\right.$ in at\%) agrees reasonably well with the EDX data of $\mathrm{Ti}_{41.6} \mathrm{Ni}_{40} \mathrm{Sn}_{18.4}$. The interatomic distances are listed in Table S1 (in the ESI $\dagger$ ) and essentially comply with the sum of the metal $\operatorname{radii}^{32}\left(R_{\mathrm{Ti}}=0.1462 \mathrm{~nm}, R_{\mathrm{Ni}}=0.1246 \mathrm{~nm}, R_{\mathrm{Sn}}=\right.$ $0.1545 \mathrm{~nm})$. As a general result of our specimens, Rietveld refinements and SEM data in all cases are consistent with a small amount of the $4^{\text {th }}$ group element $T$ in the Sn-site (Wyckoff site $4 d\left(0, \frac{1}{2}, \frac{1}{4}\right)$ ) in a random distribution $\mathrm{Sn} / \mathrm{T}$ yielding slightly non-stoichiometric formulae $\{\mathrm{Ti}, \mathrm{Zr}, \mathrm{Hf}\}_{2+x} \mathrm{Ni}_{2} \mathrm{Sn}_{1-x}$. The implication of this non-stoichiometry is a minor $\mathrm{T}$ for $\mathrm{Sn}$ substitution in the distorted CsCl-slabs TSn, which together with distorted $\mathrm{AlB}_{2}$-type slabs $\mathrm{TNi}_{2}$ form the $\mathrm{U}_{2} \mathrm{Pt}_{2} \mathrm{Sn}$-type structure.

Selected area electron diffraction (SAED) patterns were collected by TEM from thin lamellae of the $\mathrm{Ti}_{2+x} \mathrm{NiSn}_{1-x}$ phase (using the arc-melted alloy $\mathrm{Ti}_{44} \mathrm{Ni}_{40} \mathrm{Sn}_{16}$ ). With full confir-

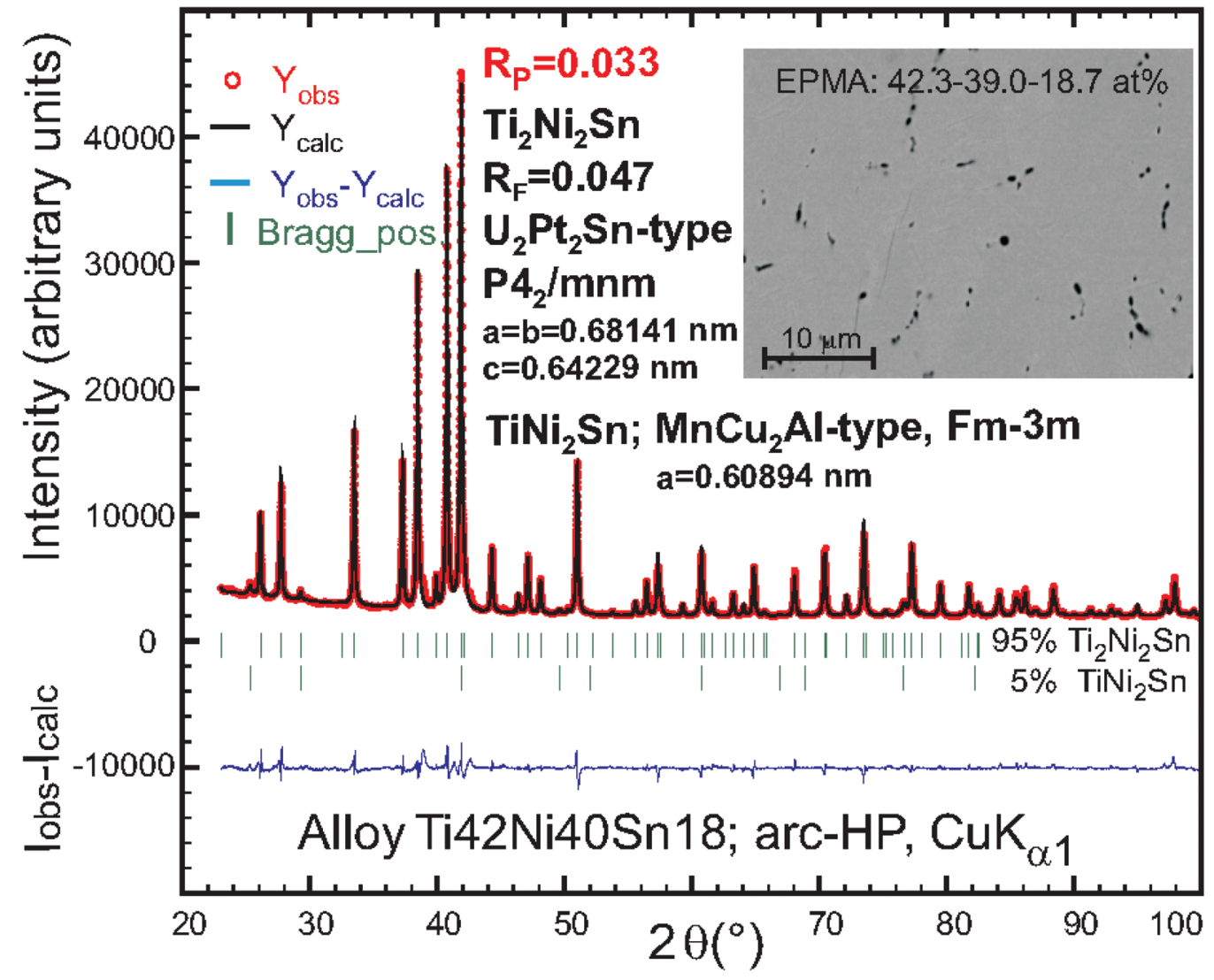

Fig. 1 Rietveld refinement of the hot-pressed sample prepared from the nominal composition $\mathrm{Ti}_{42} \mathrm{Ni}_{40} \mathrm{Sn}_{18}$ (in at\%). The inset shows the microstructure and the EDX phase composition of $\mathrm{Ti}_{2+x} \mathrm{Ni}_{2} \mathrm{Sn}_{1-x}, x=0.115$ from the corresponding electron backscatter photo. 
Table 1 X-ray single crystal data for $\mathrm{Ti}_{2+x} \mathrm{Ni}_{2} \mathrm{Sn}_{1-x}, x \sim 0.13(1)$; with the $\mathrm{U}_{2} \mathrm{Pt}_{2} \mathrm{Sn}$-type, space group $\mathrm{P} 4_{2} / \mathrm{mnm}$, (No. 136 , origin at the centre); standardized with the program Structure Tidy. ${ }^{16}$ Mo Ko-radiation; $3^{\circ} \leq 2 \theta \leq 73.0^{\circ} ; \omega$-scans, anisotropic displacement parameters $U_{i j}$ in $\left[10^{2} \mathrm{~nm}^{2}\right]$

\section{Parameter/compound}

$\mathrm{ii}_{2+x} \mathrm{Ni}_{2} \mathrm{Sn}_{1-x}, x \sim 0.13(1)$

Composition from EDX in at\% $\left( \pm 0.8 \quad \mathrm{Ti}_{41.6} \mathrm{Ni}_{40.0} \mathrm{Sn}_{18.4}\right.$ at $\%)$

Compos. from refinement in at $\%$

Formula from refinement

Linear absorption coeff. in $\mathrm{mm}^{-1}$

Density in $\mathrm{Mg} \mathrm{m}^{-3}$

$a[\mathrm{~nm}] ; c[\mathrm{~nm}]$

Reflections in refinement

Number of variables

$R_{\mathrm{F}}{ }^{2}=\sum\left|F_{\mathrm{o}}{ }^{2}-F_{\mathrm{c}}{ }^{2}\right| / \sum F_{\mathrm{o}}{ }^{2}$

$R_{\text {Int }}$

$\mathrm{w} R_{2}$

GOF

$\mathrm{Ti}_{42.6} \mathrm{Ni}_{40} \mathrm{Sn}_{17.4}$

$\mathrm{Ti}_{2.13} \mathrm{NiSn}_{0.87}$

25.55

7.42

$0.68114(2) ; 0.64017(2)$

$411 \geq 4 \sigma\left(F_{\mathrm{o}}\right)$ of 417

20

0.0082

0.064

0.0172

1.318

0.49

$0.0116(3)$

Extinction (Zachariasen)

Residual density $\mathrm{e}^{-}$per $\mathrm{nm}^{3} \times 10^{3}$;

max; min

Atom parameters

Ti1: $4 g(x,-x, 0) ; x$; occ.

$U_{11}=U_{22} ; U_{33}$

$U_{23}=\mathrm{U}_{13}=0 ; U_{12}$

Ti2: $4 f(x, x, 0) ; x$; occ.

$U_{11}=U_{22} ; U_{33}$

$U_{23}=U_{13}=0 ; U_{12}$

Ni1: $8 j(x, x, z) ; x ; z$; осc.

$U_{11}=U_{22} ; U_{33}$

$U_{23}=U_{13}=0 ; U_{12}$

Sn1/Ti3: $4 d\left(0, \frac{1}{2}, \frac{1}{4}\right)$; occ.

$U_{11}=U_{22} ; U_{33} ; U_{23}=U_{13}=U_{12}=0$

Principal mean square atomic

displacements mation of the $\mathrm{U}_{2} \mathrm{Pt}_{2} \mathrm{Sn}$-type tetragonal lattice all diffraction patterns were fully indexed using the parameters listed in Table 1. No further superstructure spots were detected. Fig. 2 shows several examples of low index zone axis diffraction patterns recorded at various sample tilts together with simulated SAED patterns using software JEMS. ${ }^{33,34}$

Although Wang et al. ${ }^{35}$ confirmed the existence of $\mathrm{Ti}_{2} \mathrm{Ni}_{2} \mathrm{Sn}$ at $T \geq 600^{\circ} \mathrm{C}$, they claimed instability below $235^{\circ} \mathrm{C}$. This statement is similar to an earlier report ${ }^{36}$ on instability below $500^{\circ}$ C, which has been revised later ${ }^{9}$ and was convincingly explained by retarded reaction/diffusion kinetics at low temperatures. A long term experiment with slow cooling the $\mathrm{Ti}_{42} \mathrm{Ni}_{40} \mathrm{Sn}_{18}$ alloy $\left(5 \mathrm{~K} \mathrm{~h}^{-1}\right)$ from $1000{ }^{\circ} \mathrm{C}$ to $200{ }^{\circ} \mathrm{C}$ and additional annealing for 1 month at $200{ }^{\circ} \mathrm{C}$ revealed changes neither in XPD intensities nor in the EDX microstructure. The $\mathrm{Ti}_{2+x} \mathrm{NiSn}_{1-x}$ phase can thus safely be considered to be stable also at low temperatures.

\subsection{Physical properties}

According to the characterization by XPD and EDX, as shown in Fig. 1, S1, S2 $\uparrow$ and Table 2, the large samples $\mathrm{T}_{2+x} \mathrm{Ni}_{2} \mathrm{Sn}_{1-x}$ used for physical property measurements are close to single phase conditions with only minor amounts of secondary phases (see micrographs in Fig. 1, S1 and $\mathrm{S} 2 \dagger$ ). The three samples, $\mathrm{Ti}_{2.13} \mathrm{Ni}_{2} \mathrm{Sn}_{0.87}, \mathrm{Zr}_{2.025} \mathrm{Ni}_{2} \mathrm{Sn}_{0.975}$ and $\mathrm{Hf}_{2.055} \mathrm{Ni}_{2} \mathrm{Sn}_{0.945}$, revealed relative densities of $97.7 \%, 99.1 \%$ and $94.4 \%$ (Table 2), respectively. These data are important because physical and even more so mechanical properties strongly depend on the sample's density. For simplicity we will use the formula $\mathrm{T}_{2} \mathrm{Ni}_{2} \mathrm{Sn}$ throughout the following chapters.

3.2.1. Electrical resistivity and Seebeck coefficient. The electrical resistivity of all three compounds, $\mathrm{Ti}_{2} \mathrm{Ni}_{2} \mathrm{Sn}$, $\mathrm{Zr}_{2} \mathrm{Ni}_{2} \mathrm{Sn}$, and $\mathrm{Hf}_{2} \mathrm{Ni}_{2} \mathrm{Sn}$, displayed in Fig. 3, is metallic-like with dominant scattering obviously conditioned by off-

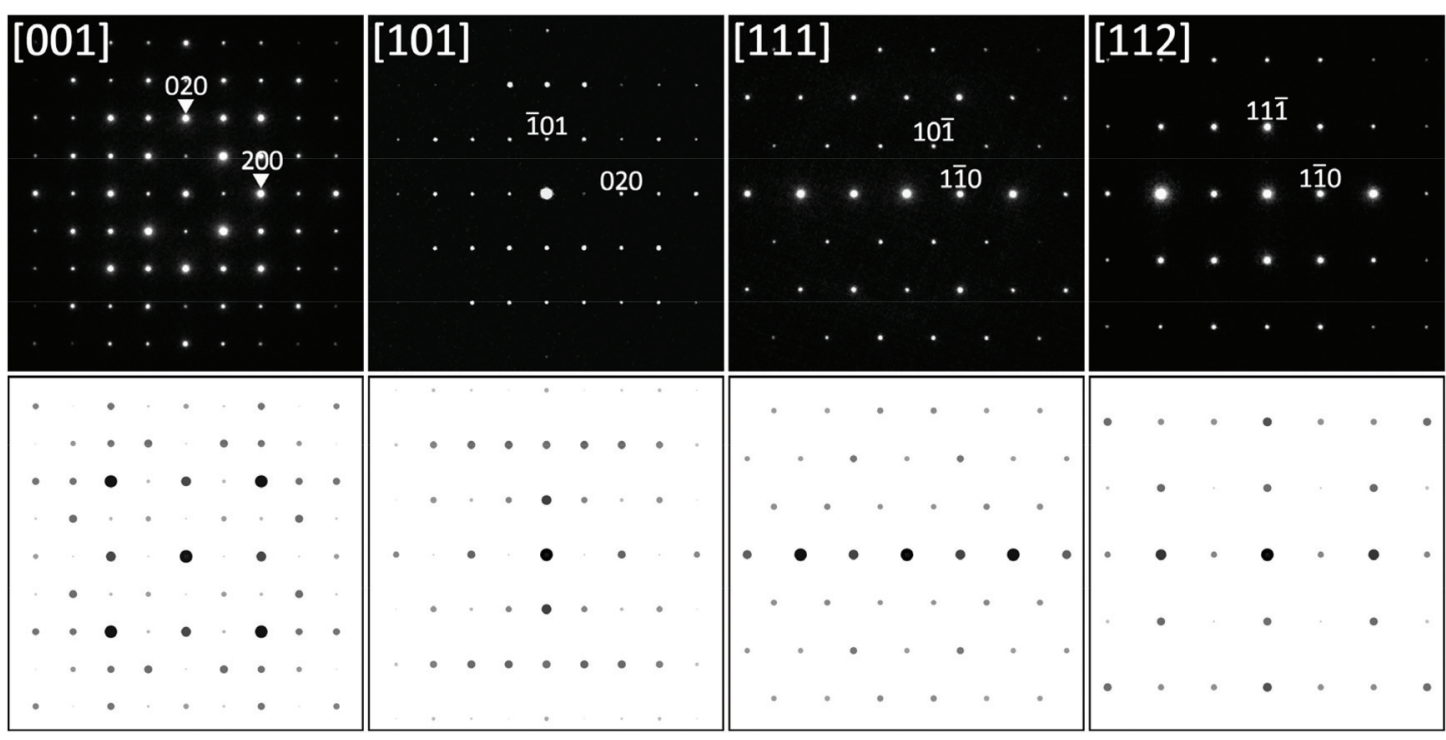

Fig. 2 SAED patterns of $\mathrm{Ti}_{2+x} \mathrm{NiSn}_{1-x}$ at various sample tilts together with the results of kinematic simulation. The intensities of spots in SAED patterns are averaged by strong dynamical effects (double diffraction). 
Table 2 Physical properties (density, elastic moduli, Debye and Einstein temperatures and magnetic susceptibilities) for compounds $\mathrm{T}_{2+x} \mathrm{Ni}_{2} \mathrm{Sn}_{1-x}(\mathrm{~T}$ $=\mathrm{Ti}, \mathrm{Zr}$, and $\mathrm{Hf}$ ) of the $\mathrm{U}_{2} \mathrm{Pt}_{2} \mathrm{Sn}$-type

\begin{tabular}{|c|c|c|c|c|}
\hline Parameter/compound & $\mathrm{Ti}_{2+x} \mathrm{Ni}_{2} \mathrm{Sn}_{1-x}$ & $\mathrm{Zr}_{2+x} \mathrm{Ni}_{2} \mathrm{Sn}_{1-x}$ & $\mathrm{Hf}_{2+x} \mathrm{Ni}_{2} \mathrm{Sn}_{1-x}$ & Ref. \\
\hline $\begin{array}{l}\text { Formula from EDX }( \pm 0.8 \text { at } \%) \\
\text { Lattice param. }[\mathbf{n m}]\end{array}$ & $\begin{array}{l}\mathrm{Ti}_{42.3} \mathrm{Ni}_{39.0} \mathrm{Sn}_{18.7}, x=0.115 \\
a=b=0.68142(1), c=0.64229(1)\end{array}$ & $\begin{array}{l}\mathrm{Zr}_{40.5} \mathrm{Ni}_{39.9} \mathrm{Sn}_{19.6}, x=0.025 \\
a=b=0.70663(1), c=0.68233(1)\end{array}$ & $\begin{array}{l}\mathrm{Hf}_{41.1} \mathrm{Ni}_{40.4} \mathrm{Sn}_{18.5}, x=0.055 \\
a=b=0.70597(1), c=0.67545(1)\end{array}$ & $\begin{array}{l}\text { This work } \\
\text { This work }\end{array}$ \\
\hline \multicolumn{5}{|l|}{ Density } \\
\hline $\mathrm{X}$-ray density $d_{\mathrm{X}}\left[\mathrm{Mg} \mathrm{m}^{-3}\right]$ & 7.27 & 8.17 & 11.84 & This work \\
\hline meas. density $d_{\mathrm{A}}\left[\mathrm{Mg} \mathrm{m}^{-3}\right]$ & 7.10 & 8.09 & 11.18 & This work \\
\hline rel. density $d_{\mathrm{r}}$ in \% & 97.7 & 99.1 & 94.4 & This work \\
\hline \multicolumn{5}{|l|}{ Elastic moduli } \\
\hline$E_{\text {eff }}$ (nanoindentation) $[\mathrm{GPa}]$ & 230 & 205 & 215 & This work \\
\hline$E$ (RUS) $/ E$ (nanoindent.) $[\mathrm{GPa}]$ & $-/ 209^{a}$ & $171 / 186^{a}$ & $-/ 195^{a}$ & This work \\
\hline Poisson number $\nu$ (RUS) & $0.31^{a}$ & 0.31 & $0.31^{a}$ & This work \\
\hline Bulk mod. $B$ [GPa] & $-/ 180^{a}$ & $147 / 160^{a}$ & $-/ 168^{a}$ & This work \\
\hline Shear mod. $G$ [GPa] & $-/ 80^{a}$ & $66 / 71^{a}$ & $-/ 75^{a}$ & This work \\
\hline$C_{11}[\mathrm{GPa}]$ & $-/ 287^{a}$ & $234 / 255^{a}$ & $-/ 268^{a}$ & This work \\
\hline$E$ (Voigt-Reuss-Hill) [GPa] & - & - & 175.3-169.4-172.4 & $10^{b}$ \\
\hline$\nu$ (Voigt-Reuss-Hill) [GPa] & - & - & $0.294-0.301-0.297$ & $10^{b}$ \\
\hline B (Voigt-Reuss-Hill) [GPa] & - & - & $141.9-141.7-141.8$ & $10^{b}$ \\
\hline G (Voigt-Reuss-Hill) [GPa] & - & - & $67.7-65.12-66.42$ & $10^{b}$ \\
\hline \multicolumn{5}{|l|}{ Hardness } \\
\hline$H_{\mathrm{IT}}[\mathrm{GPa}]$ & 11 & 10 & 11 & This work \\
\hline \multicolumn{5}{|l|}{ Debye and Einstein temp. } \\
\hline$\theta_{\mathrm{D}}($ Anderson) $[\mathrm{K}]$ & - & 309 & - & This work \\
\hline$\theta_{\mathrm{D}}$ (Bl.G-resistivityfit) [K] & 318 & 298 & 273 & This work \\
\hline$\theta_{\mathrm{D}}$ (Bl.G-resistivityfit) [K] & - & 223 & - & 7 \\
\hline$\theta_{\mathrm{D}} / \theta_{\mathrm{E}}$ (Debye/Einst-Cp) $[\mathrm{K}]$ & $370 / 154$ & $354 / 147$ & $319 / 129$ & This work \\
\hline$\theta_{\mathrm{D}}^{\mathrm{LT}}\left(-\mathrm{C}^{2}\right)$ & 373 & 357 & 318 & This work \\
\hline$\theta_{\mathrm{D}} / \theta_{\mathrm{E}}$ (thermal exp.) $[\mathrm{K}]$ & - & $331 / 128$ & - & This work \\
\hline \multicolumn{5}{|l|}{ Magnetic properties } \\
\hline Susceptibility at RT $\left[\mathrm{emu} \mathrm{mol}^{-1}\right]$ & - & - & $3.18 \times 10^{-4}$ & 8 \\
\hline$\left[\mathrm{emu} \mathrm{mol}{ }^{-1}\right]$ & - & $2.3(1) \times 10^{-4}$ & - & 7 \\
\hline
\end{tabular}

${ }^{a}$ Calculated from nano-indentation data with $\nu_{\mathrm{RUS}}$ of $\mathrm{Zr}_{2} \mathrm{Ni}_{2} \mathrm{Sn} .{ }^{b}$ Elastic properties analysed with the program $\mathrm{ELATE}^{10}$ using the $\mathrm{Mo}_{2} \mathrm{FeB}_{2}$-type subcell only.

stoichiometry and grain boundaries, i.e. showing relatively large values of the residual resistivity $\rho_{0} \sim 213 \mu \Omega \mathrm{cm}$, $\sim 52 \mu \Omega \mathrm{cm}$, and $\sim 184 \mu \Omega \mathrm{cm}$, respectively. The lowest absolute resistivity values throughout the temperature range of $4.2 \mathrm{~K}$ to $\sim 800 \mathrm{~K}$ are observed for $\mathrm{Zr}_{2} \mathrm{Ni}_{2} \mathrm{Sn}$ with the highest relative density and composition closest to an ideal $2: 2: 1$ stoichiometry within the samples of the present investigation. $\mathrm{Zr}_{2} \mathrm{Ni}_{2} \mathrm{Sn}$ resistivity data reported earlier, ${ }^{7}$ shown as an inset in Fig. 3, appear closer to current $\mathrm{Ti}_{2} \mathrm{Ni}_{2} \mathrm{Sn}$ and $\mathrm{Hf}_{2} \mathrm{Ni}_{2} \mathrm{Sn}$ data and thus indicate some variabilities of the absolute electrical resistivity most likely depending on stoichiometry, sample density and possibly also on thermal history (annealing).

For the practical use of these compounds as thermoelectric materials the quality measure is the figure of merit $\mathrm{ZT}=S^{2} T$ / $\rho \lambda$, where $S$ is the Seebeck coefficient, $\rho$ is the electrical resistivity and $\lambda$ is the thermal conductivity. Fig. 4 depicts the temperature $(300 \mathrm{~K}-800 \mathrm{~K})$ dependent Seebeck coefficient, $S(T)$. For all three compounds the Seebeck coefficient is rather low. Whereas for $\mathrm{Ti}_{2} \mathrm{Ni}_{2} \mathrm{Sn}$ and $\mathrm{Hf}_{2} \mathrm{Ni}_{2} \mathrm{Sn} S(T)$ is increasing with increasing temperature, $\mathrm{Zr}_{2} \mathrm{Ni}_{2} \mathrm{Sn}$ exhibits a flat maximum at around $800 \mathrm{~K}$. The power factor, calculated as pf $=S^{2} / \rho$, is influenced mainly by the Seebeck coefficient and is therefore also increasing with increasing temperature (see Fig. 4). It reaches $\mathrm{pf}=0.075 \mathrm{~mW} \mathrm{~m}{ }^{-1} \mathrm{~K}^{-2}$ for $\mathrm{Ti}_{2} \mathrm{Ni}_{2} \mathrm{Sn}$ at $840 \mathrm{~K}$, pf $=$ $0.06 \mathrm{~mW} \mathrm{~m}^{-1} \mathrm{~K}^{-2}$ at $840 \mathrm{~K}$ for $\mathrm{Hf}_{2} \mathrm{Ni}_{2} \mathrm{Sn}$ and $\mathrm{pf}=0.04$ at $807 \mathrm{~K}$ for $\mathrm{Zr}_{2} \mathrm{Ni}_{2} \mathrm{Sn}$.

To estimate the thermal conductivity we took for $\lambda_{\min }$ a theoretical value $\left(2.32 \mathrm{~mW} \mathrm{~cm}{ }^{-1} \mathrm{~K}^{-1}\right)$ of a glass that was derived from formula (5): ${ }^{37}$

$$
\lambda_{\min }=\left(\frac{3 n}{4 \pi}\right)^{1 / 3} \frac{k_{\mathrm{B}}^{2} T^{2}}{\hbar \theta_{\mathrm{D}}} \int_{0}^{\theta_{\mathrm{D}} / T} \frac{x^{3} e^{x}}{\left(e^{x}-1\right)^{2}} \mathrm{~d} x
$$

where $n=N / V$ is the number of atoms per unit volume, $k_{\mathrm{B}}$ is the Boltzmann constant, $\hbar$ is the reduced Planck's constant, $\theta_{\mathrm{D}}$ is the Debye temperature and $x=\hbar \omega / k_{\mathrm{B}} T$. By adding $\lambda_{\text {min }}$ $\sim 2.32 \mathrm{~mW} \mathrm{~cm}^{-1} \mathrm{~K}^{-1}$ to the electron part of the thermal conductivity, $\lambda_{\mathrm{e}}$ (from the Wiedemann-Franz law, $\lambda_{\mathrm{e}}=L_{0} T / \rho(T)$ with the Lorenz number $\left(L_{0}=2.44 \times 10^{-8} \mathrm{~W} \Omega \mathrm{K}^{-2}\right)$, and by using the respective highest power factor of each compound, the following ZT values were obtained: for $\mathrm{Ti}_{2} \mathrm{Ni}_{2} \mathrm{Sn} \mathrm{ZT} \sim$ 0.007 at $840 \mathrm{~K}$, for $\mathrm{Zr}_{2} \mathrm{Ni}_{2} \mathrm{Sn} \mathrm{ZT} \sim 0.03$ at $807 \mathrm{~K}$ and for $\mathrm{Hf}_{2} \mathrm{Ni}_{2} \mathrm{Sn} \mathrm{ZT} \sim 0.005$ at $840 \mathrm{~K}$. With these rather low ZT 


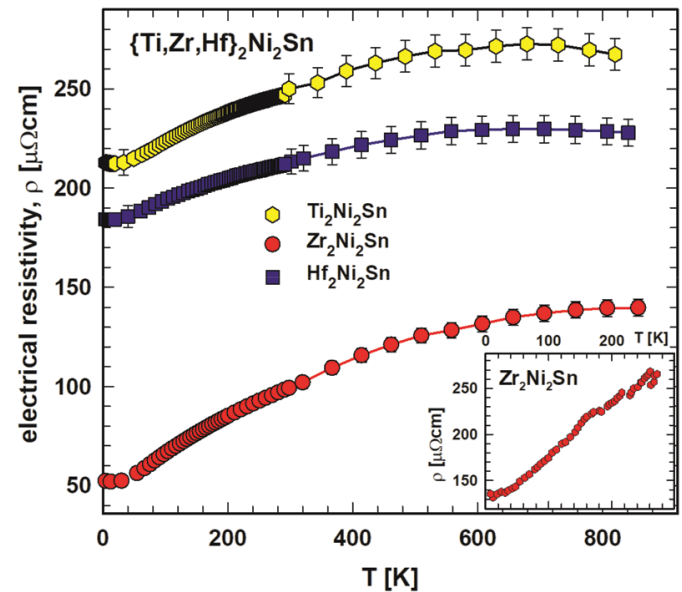

Fig. $3\{\mathrm{Ti}, \mathrm{Zr}, \mathrm{Hf}\}_{2} \mathrm{Ni}_{2} \mathrm{Sn}$ : electrical resistivity, $\rho$, vs. temperature, $T$, with the respective fit (see text). Inset: electrical resistivity, $\rho(T)$, for $\mathrm{Zr}_{2} \mathrm{Ni}_{2} \mathrm{Sn}$ from ref. 7.

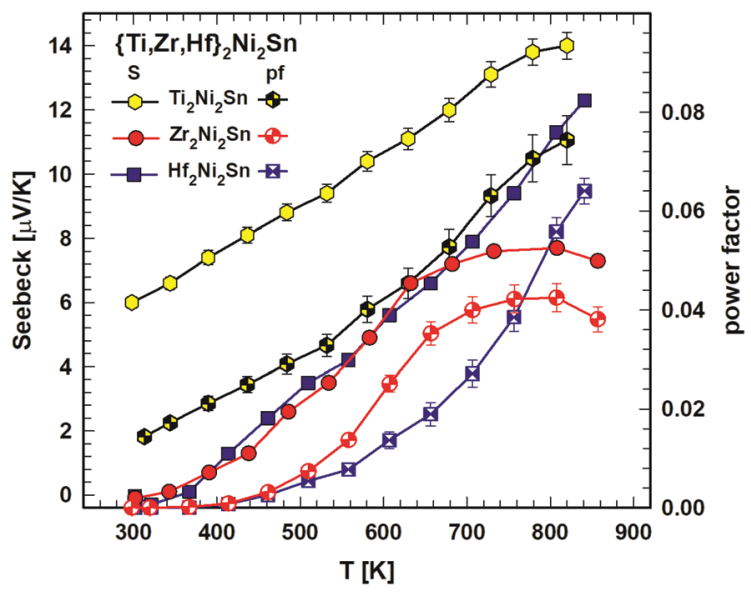

Fig. $4\{\mathrm{Ti}, \mathrm{Zr}, \mathrm{Hf}\}_{2} \mathrm{Ni}_{2} \mathrm{Sn}$ : Seebeck coefficient, $\mathrm{S}$, vs. temperature, $T$ (left scale) and power factor, pf, vs. temperature, $T$ (right scale).

values, compounds $\mathrm{T}_{2} \mathrm{Ni}_{2} \mathrm{Sn}$ do not qualify as thermoelectric materials.

3.2.2. Specific heat. To get information on the lattice dynamics of the compounds, heat capacity measurements were carried out for $\mathrm{Ti}_{2} \mathrm{Ni}_{2} \mathrm{Sn}, \mathrm{Zr}_{2} \mathrm{Ni}_{2} \mathrm{Sn}$ and $\mathrm{Hf}_{2} \mathrm{Ni}_{2} \mathrm{Sn}$. The specific heat, $C_{\mathrm{p}}$, at low temperatures of simple non-magnetic materials can be expressed as the sum of the electronic and the lattice contribution according to eqn (6):

$$
C_{\mathrm{p}}=C_{\mathrm{el}}+C_{\mathrm{ph}} \sim \gamma T+\beta T^{3} \text { with } \beta=12 R \pi^{4} n / 5 \theta_{\mathrm{D}}{ }^{3}
$$

where $\gamma$ is the electronic Sommerfeld coefficient and $\beta$ corresponds to the low temperature limit of the Debye temperature $\theta_{\mathrm{D}}, R$ is the gas constant and $n$ is the number of atoms in the formula unit.

Fig. 5 depicts the temperature dependent heat capacity $(2<$ $T<140 \mathrm{~K})$ as $C_{\mathrm{p}}(T)$ of $\mathrm{Ti}_{2} \mathrm{Ni}_{2} \mathrm{Sn}, \mathrm{Zr}_{2} \mathrm{Ni}_{2} \mathrm{Sn}$ and $\mathrm{Hf}_{2} \mathrm{Ni}_{2} \mathrm{Sn}$. The

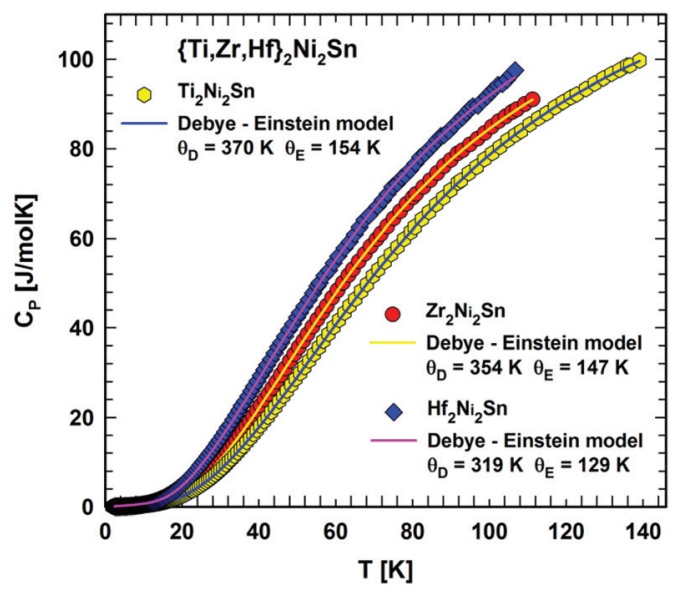

Fig. 5 Temperature dependent heat capacity, $C_{p}$, for $\{\mathrm{Ti}, \mathrm{Zr}, \mathrm{Hf}\}_{2} \mathrm{Ni}_{2} \mathrm{Sn}$. The respective line shows a fit according to eqn. (7).

$C_{\mathrm{p}}(T)$ dependence is smooth without any significant feature of a phase transition in the measured temperature range, but the $C_{\mathrm{p}} / T$ vs. $T^{2}$ curve (Fig. 6) shows a slight upturn below $\sim 12 \mathrm{~K}$ indicating a contribution from a very small amount of magnetic impurities. By excluding this upturn and applying eqn (6), the heat capacity of $\mathrm{Ti}_{2} \mathrm{Ni}_{2} \mathrm{Sn}, \mathrm{Zr}_{2} \mathrm{Ni}_{2} \mathrm{Sn}$ and $\mathrm{Hf}_{2} \mathrm{Ni}_{2} \mathrm{Sn}$ could be fitted (dashed lines) at temperatures from $16 \mathrm{~K}^{2}$ to $60 \mathrm{~K}^{2}$. This analysis yields Sommerfeld coefficients of $\gamma=14.3(3) \mathrm{mJ}$ $\mathrm{mol}^{-1} \mathrm{~K}^{-2}, \gamma=10(1) \mathrm{mJ} \mathrm{mol}^{-1} \mathrm{~K}^{-2}$ and $\gamma=9.1(5) \mathrm{mJ} \mathrm{mol}^{-1} \mathrm{~K}^{-2}$, respectively. The values obtained are comparable with those calculated from the reported magnetic susceptibility data of $\mathrm{Zr}_{2} \mathrm{Ni}_{2} \mathrm{Sn}^{7}$ and $\mathrm{Hf}_{2} \mathrm{Ni}_{2} \mathrm{Sn}^{8}{ }^{8}$ From the Sommerfeld constant $\gamma=$ $\pi^{2} N_{\mathrm{A}} k_{\mathrm{B}}{ }^{2} \operatorname{DOS}\left(E_{\mathrm{F}}\right) / 3$ and measured Pauli magnetic susceptibility $\chi_{\mathrm{P}}=\mu_{\mathrm{B}}^{2} N_{\mathrm{A}} \operatorname{DOS}\left(E_{\mathrm{F}}\right)$, we may use the relation between $\chi_{\mathrm{P}}(\mathrm{emu}$ $\left.\mathrm{mol}^{-1}\right)$ and $\gamma\left(\mathrm{mJ} \mathrm{mol}^{-1} \mathrm{~K}^{-2}\right): \chi_{\mathrm{P}}=1.37148 \times 10^{-5} \gamma$. Taking into account the Landau diamagnetic susceptibility $\left(\chi_{\mathrm{L}}\right)$, the measured susceptibility is $\chi=S \chi_{\mathrm{P}}+\chi_{\mathrm{L}}=S \chi_{\mathrm{P}}-\chi_{\mathrm{P}} / 3$, and a realistic Stoner enhancement factor $S \sim 2$ yields the Sommerfeld

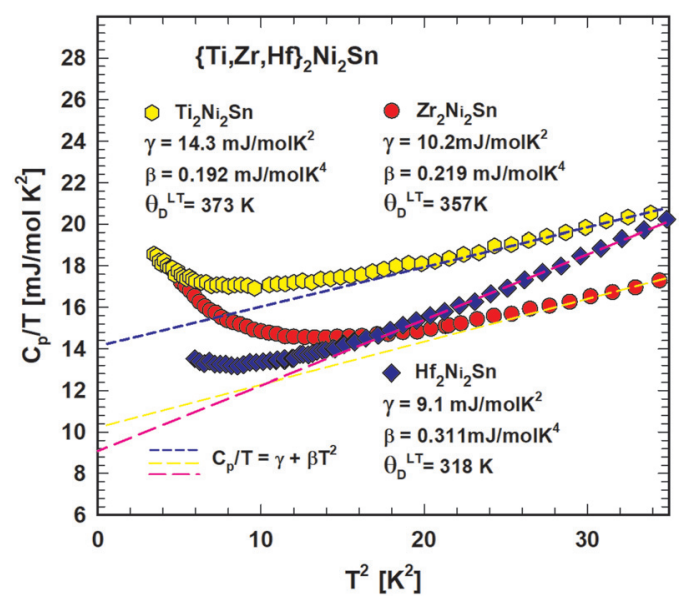

Fig. $6 C_{\mathrm{p}} / T$ vs. $T^{2}$ of $\{\mathrm{Ti}, \mathrm{Zr}, \mathrm{Hf}\}_{2} \mathrm{Ni}_{2} \mathrm{Sn}$. 
constants of the order of $10 \mathrm{~mJ} \mathrm{~mol}^{-1} \mathrm{~K}^{-2}$ for these compounds, which compares reasonably well with the present experimental values. With $\beta=0.192 \mathrm{~mJ} \mathrm{~mol}^{-1} \mathrm{~K}^{-4}$ for $\mathrm{Ti}_{2} \mathrm{Ni}_{2} \mathrm{Sn}, \beta=0.219 \mathrm{~mJ} \mathrm{~mol} \mathrm{~K}^{-1}$ for $\mathrm{Zr}_{2} \mathrm{Ni}_{2} \mathrm{Sn}$ and $\beta=$ $0.311 \mathrm{~mJ} \mathrm{~mol}^{-1} \mathrm{~K}^{-4}$ for $\mathrm{Hf}_{2} \mathrm{Ni}_{2} \mathrm{Sn}$ the corresponding Debye temperatures could be extracted via eqn (6) in the low temperature (LT) range: $\theta_{\mathrm{D}}^{\mathrm{LT}}=373(7) \mathrm{K}, 357(14) \mathrm{K}$ and 318(10) $\mathrm{K}$.

To explore the phonon spectrum a more detailed description is necessary: $C_{\mathrm{P}}=C_{\mathrm{el}}+C_{\mathrm{ph}}$

$$
C_{\mathrm{P}}=\gamma T+\frac{3 c_{\mathrm{D}} R}{\omega_{\mathrm{D}}^{3}} \int_{0}^{\omega_{D}} \frac{\omega^{2}\left(\frac{\omega}{2 T}\right)^{2}}{\sinh ^{2}\left(\frac{\omega}{2 T}\right)} \mathrm{d} \omega+\sum_{i=1}^{3} c_{E_{i}} R \frac{\left(\frac{\omega_{E_{i}}}{2 T}\right)^{2}}{\sinh ^{2}\left(\frac{\omega_{E_{i}}}{2 T}\right)},
$$

where $C_{\mathrm{ph}}(T)$ takes into account the Debye and Einstein modes (with 3 acoustic and 57 optical branches). From the least-squares fit to the $C_{\mathrm{P}}(T)$ data of $\mathrm{Ti}_{2} \mathrm{Ni}_{2} \mathrm{Sn}, \mathrm{Zr}_{2} \mathrm{Ni}_{2} \mathrm{Sn}$ and $\mathrm{Hf}_{2} \mathrm{Ni}_{2} \mathrm{Sn}$ the following Debye and Einstein temperatures could be extracted (see Fig. 5): $\theta_{\mathrm{D}}=370 \mathrm{~K}$ and $\theta_{\mathrm{E}}=154 \mathrm{~K}, \theta_{\mathrm{D}}=354 \mathrm{~K}$ and $\theta_{\mathrm{E}}=147 \mathrm{~K}$ and $\theta_{\mathrm{D}}=329 \mathrm{~K}$ and $\theta_{\mathrm{E}}=129 \mathrm{~K}$. There is a good agreement between these $\theta_{\mathrm{D}}$ values and the corresponding LT data.

\subsection{Mechanical properties}

Not only the thermoelectric materials' mechanical properties (hardness, elastic moduli and thermal expansion) are of importance, but also they govern any technical use per se or in composites etc. Therefore several high resolution maps of mechanical properties were established from various parts of the sample surfaces of $\mathrm{T}_{2+x} \mathrm{Ni}_{2} \mathrm{Sn}_{1-x}(\mathrm{~T}=\mathrm{Ti}, \mathrm{Zr}, \mathrm{Hf})$ using the XPM nanoindentation mode. The maps consisted of data obtained from the analysis of 225 to 400 loading/unloading curves. The hardness $\left(H_{\mathrm{IT}}\right)$ and reduced elastic modulus $\left(E_{\mathrm{r}}\right)$ were calculated from the curves using the standard evaluation procedure according to Oliver and Pharr. ${ }^{38}$ From measured $E_{\mathrm{r}}$ the so-called effective indentation modulus $E_{\text {eff }}$ was calculated by introducing the material parameters of the diamond indenter. With the knowledge of the Poisson ratio $\nu$ also the Young's modulus $(E)$ of the sample can be determined from nanoindentation. The relationship between $E_{\mathrm{r}}, E_{\text {eff }}$ and $E$ may be expressed using the following formula:

$$
\frac{1}{E_{\mathrm{r}}}=\frac{1-\nu^{2}}{E}+\frac{1-\nu_{i}^{2}}{E_{i}}=\frac{1}{E_{\mathrm{eff}}}+\frac{1-\nu_{i}^{2}}{E_{i}} .
$$

Here $E_{\mathrm{i}}$ and $\nu_{\mathrm{i}}$ are Young's modulus and the Poisson ratio of the diamond indenter, and $E$ and $\nu$ are the corresponding parameters of the sample studied.

Fig. 7 displays the maps of hardness $\left(H_{\mathrm{IT}}\right)$ and effective elastic modulus $\left(E_{\text {eff }}\right.$ ) obtained on the $\mathrm{Ti}_{2+x} \mathrm{Ni}_{2} \mathrm{Sn}_{1-x}$ sample under as cast conditions revealing several phases on the mechanical property maps. According to the analytical elec-
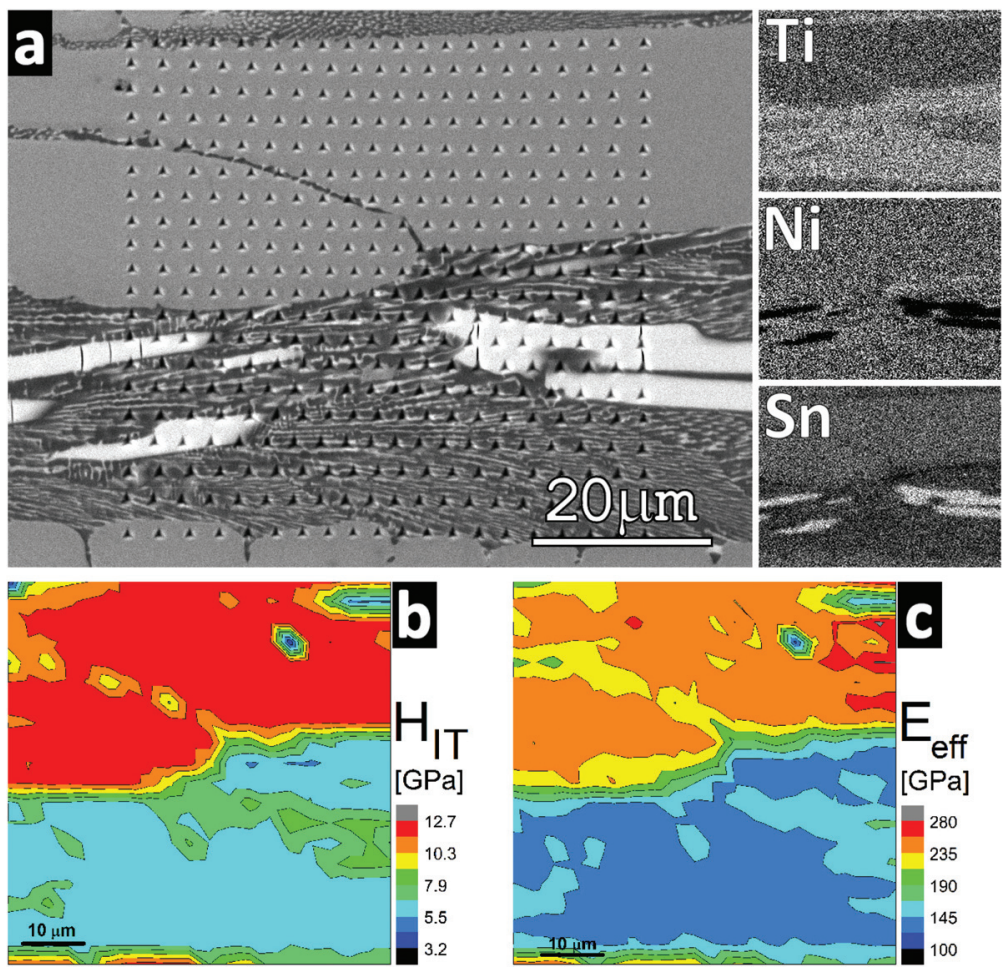

Fig. 7 Mechanical property mapping on the arc melted alloy $\mathrm{Ti}_{44} \mathrm{Ni}_{40} \mathrm{Sn}_{16}$ (in at\%): (a) SEM image (the signal of backscattered electrons) of $20 \times 20$ indents carried out with a maximum load of $10 \mathrm{mN}$ on the polished sample surface together with the elemental EDX maps of Ti, $\mathrm{Ni}$, and $\mathrm{Sn}$. Matrix $\mathrm{Ti}_{2+x} \mathrm{Ni}_{2} \mathrm{Sn}_{1-x}\left(\mathrm{Ti}_{41.6} \mathrm{Ni}_{40.0} \mathrm{Sn}_{18.4}\right.$ at\%; EDX), white phase $\mathrm{Ti}_{5} \mathrm{NiSn}_{3}\left(\mathrm{Ti}_{55.5} \mathrm{Ni}_{11.4} \mathrm{Sn}_{33.1}\right)$, and dark eutectic: $\mathrm{Ti}_{47.7} \mathrm{Ni}_{43.5} \mathrm{Sn}_{8.8}$. (b) map of hardness; (c) map of effective elastic modulus. 


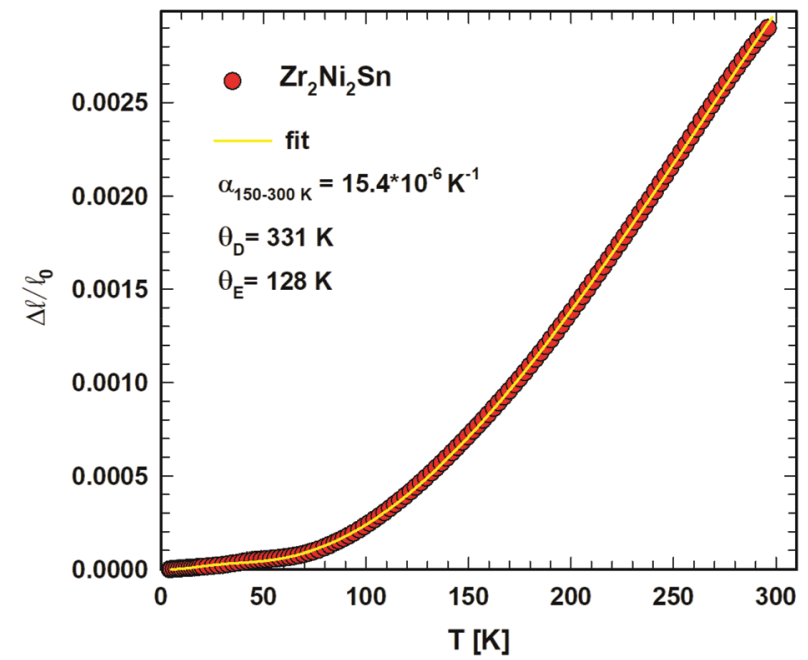

Fig. 8 Length change $\Delta \ell / \ell_{0} v s$. temperature, $T$, with a fit (the solid line) for $\mathrm{Zr}_{2} \mathrm{Ni}_{2} \mathrm{Sn}$. tron microscopy results the majority phase $\mathrm{Ti}_{2+x} \mathrm{Ni}_{2} \mathrm{Sn}_{1-x}$ was the hardest phase $\left(H_{\mathrm{IT}}=11 \pm 1 \mathrm{GPa} ; E_{\text {eff }}=230 \pm 20 \mathrm{GPa}\right)$. The Sn-rich phase (the brightest phase in Fig. $7(\mathrm{a})$; i.e. $\mathrm{Ti}_{5} \mathrm{NiSn}_{3}$ ) exhibited a hardness around $7 \pm 1 \mathrm{GPa}$ and an effective elastic modulus around $150 \pm 12 \mathrm{GPa}$. The fine mixture of the Sn-rich phase including a phase close to TiNi (in bottom half of the maps) exhibited $H_{\mathrm{IT}}=5 \pm 1 \mathrm{GPa}$ and $E_{\text {eff }}=120 \pm 10 \mathrm{GPa}$.

In contrast to the case of $\mathrm{Ti}_{2+x} \mathrm{Ni}_{2} \mathrm{Sn}_{1-x}$, the mechanical property maps obtained from the hot-pressed alloys $\mathrm{T}_{2+x} \mathrm{Ni}_{2} \mathrm{Sn}_{1-x}(\mathrm{~T}=\mathrm{Zr}$ and $\mathrm{Hf})$ yielded rather uniform values reflecting the experimental error caused mainly by the surface roughness of the samples (which is a significant source of error in the case of nanoindentation). The hardness obtained for both $\mathrm{Zr}$ and $\mathrm{Hf}$ - containing samples was similar: in the range from 10 to $11 \mathrm{GPa}$. The effective elastic modulus was slightly higher in the case of $\mathrm{Hf}_{2+x} \mathrm{Ni}_{2} \mathrm{Sn}_{1-x}\left(E_{\text {eff }}=215 \pm 15\right.$ $\mathrm{GPa}$ ), whereas in the case of $\mathrm{Zr}_{2+x} \mathrm{Ni}_{2} \mathrm{Sn}_{1-x}$ the average value was $205 \pm 10 \mathrm{GPa}$.

Table 3 Calculated lattice parameters $(\mathrm{a}, \mathrm{c}, \mathrm{V})$, Sommerfeld coefficient $(\gamma)$, ratio of the thermal effective mass to the electron mass $\left(m_{\mathrm{th}} / m_{\mathrm{e}}\right)$, and the enthalpy of formation $\left(\Delta H_{f}\right)$ of the $\mathrm{Ti}_{2} \mathrm{Ni}_{2} \mathrm{Sn}, \mathrm{Zr}_{2} \mathrm{Ni}_{2} \mathrm{Sn}$, and $\mathrm{Hf}_{2} \mathrm{Ni}_{2} \mathrm{Sn}$ compounds

\begin{tabular}{lllllll}
\hline & $a(\mathrm{~nm})$ & $c(\mathrm{~nm})$ & $V\left(\mathrm{~nm}^{3}\right)$ & $\gamma\left(\mathrm{mJ} \mathrm{mol}^{-1} \mathrm{~K}^{-2}\right)$ & $m_{\mathrm{th}} / m_{\mathrm{e}}$ & $\Delta H_{\mathrm{f}}(\mathrm{meV} \mathrm{per} \mathrm{atom})$ \\
\hline $\mathrm{Ti}_{2} \mathrm{Ni}_{2} \mathrm{Sn}$ & 0.68168 & 0.64379 & 0.29916 & 6.93 & 2.06349 & -523.65516 \\
$\mathrm{Zr}_{2} \mathrm{Ni}_{2} \mathrm{Sn}$ & 0.70662 & 0.68893 & 0.34399 & 6.71 & 1.52012 & -619.1403 \\
$\mathrm{HF}_{2} \mathrm{Ni}_{2} \mathrm{Sn}$ & 0.70925 & 0.68202 & 0.34308 & 5.024 & 1.81131 & -585.14954
\end{tabular}
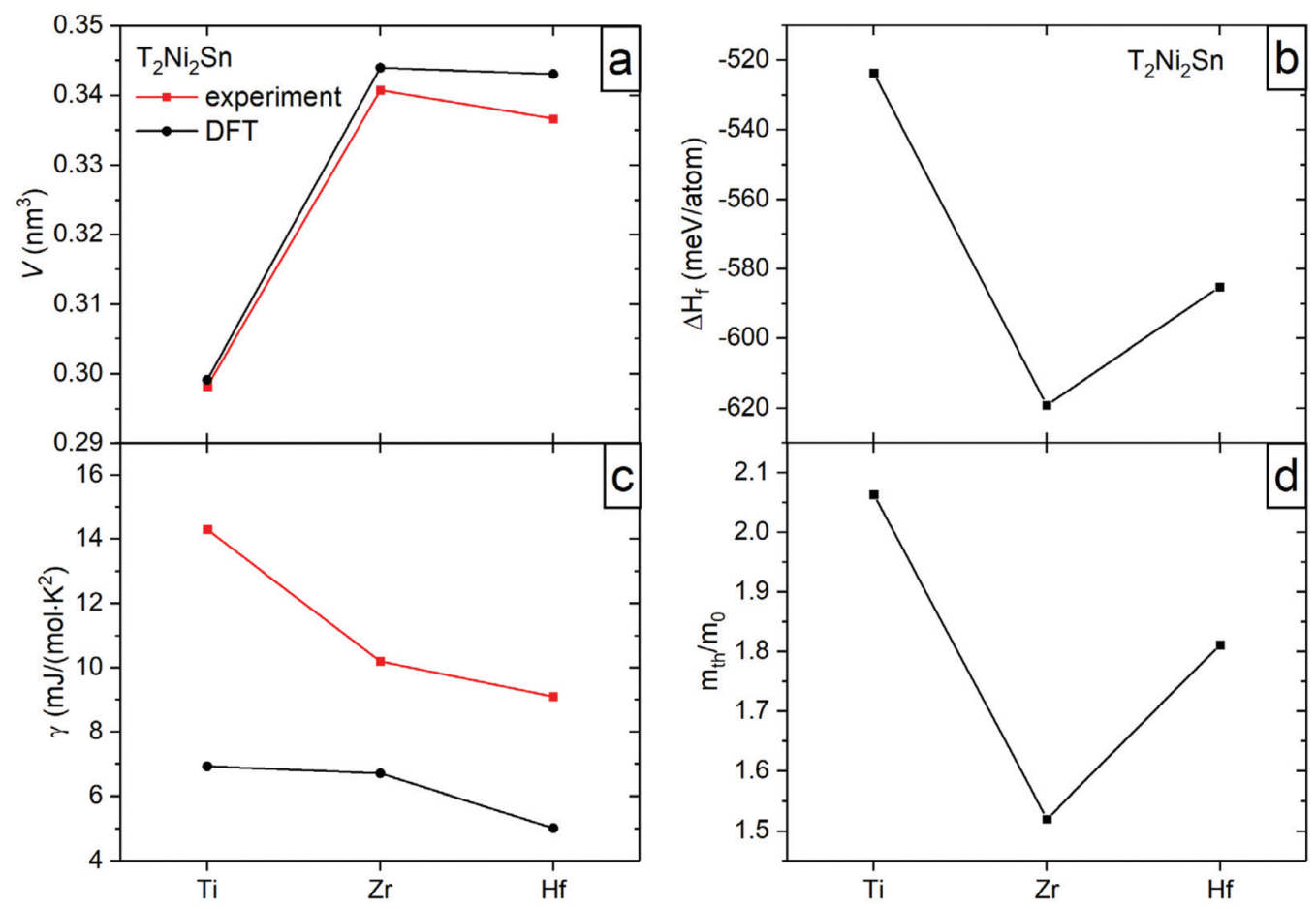

Fig. 9 Some features of compounds $\mathrm{T}_{2} \mathrm{Ni}_{2} \mathrm{Sn}(\mathrm{T}=\mathrm{Ti}, \mathrm{Zr}$, and $\mathrm{Hf}$ ) calculated by DFT: (a) experimental and theoretical values of the unit cell volume; (b) calculated enthalpy of formation; (c) experimental and DFT values of the Sommerfeld constant; (d) calculated ratio of the thermal effective mass to the electron mass. 
For $\mathrm{Zr}_{2} \mathrm{Ni}_{2} \mathrm{Sn}$ the result of resonant ultrasound spectroscopy, RUS, yielded a Young's modulus $E=171 \pm 0.7 \mathrm{GPa}$ and a Poisson ratio of $\nu=0.31 \pm 0.04$. All other elastic moduli were calculated according to eqn (1) and (2), providing a shear modulus $G=65.5 \mathrm{GPa}$, a bulk modulus $B=147 \mathrm{GPa}$ and modulus for dilation on compression $C_{12}=103 \mathrm{GPa}$. These values are in the same range as those calculated via the program ELATE ${ }^{10}$ for $\mathrm{Hf}_{2} \mathrm{Ni}_{2} \mathrm{Sn}$ with $E=175.3 \mathrm{GPa}, 169.4 \mathrm{GPa}$ and $172.4 \mathrm{GPa}$ and $\nu=$ $0.294,0.301$ and 0.297 , respectively for values according to Voigt, Reuss and Hill. Unfortunately, these data were all calcu- lated for the $\mathrm{Mo}_{2} \mathrm{FeB}_{2}$-type and not for the appropriate structural data with the $\mathrm{U}_{2} \mathrm{Pt}_{2} \mathrm{Sn}$-type. ${ }^{8}$ Using the Poisson ratio value of $\nu_{\text {RUS }}=0.31$ obtained for $\mathrm{Zr}_{2} \mathrm{Ni}_{2} \mathrm{Sn}$, it was possible to derive the elastic moduli of $\{\mathrm{Zr}, \mathrm{Hf}\}_{2} \mathrm{Ni}_{2} \mathrm{Sn}$ from $E_{\text {eff }}$ according to eqn (1) and (8). The value of $186 \pm 9 \mathrm{GPa}\left(\mathrm{Zr}_{2} \mathrm{Ni}_{2} \mathrm{Sn}\right)$ is slightly higher than the value obtained by means of RUS. The possible reason for this difference is that the nanoindentation results are measured in shallow depths (i.e. the indentation response is obtained from small volumes of the sample, where the probability of defect occurrence is low) compared to the RUS
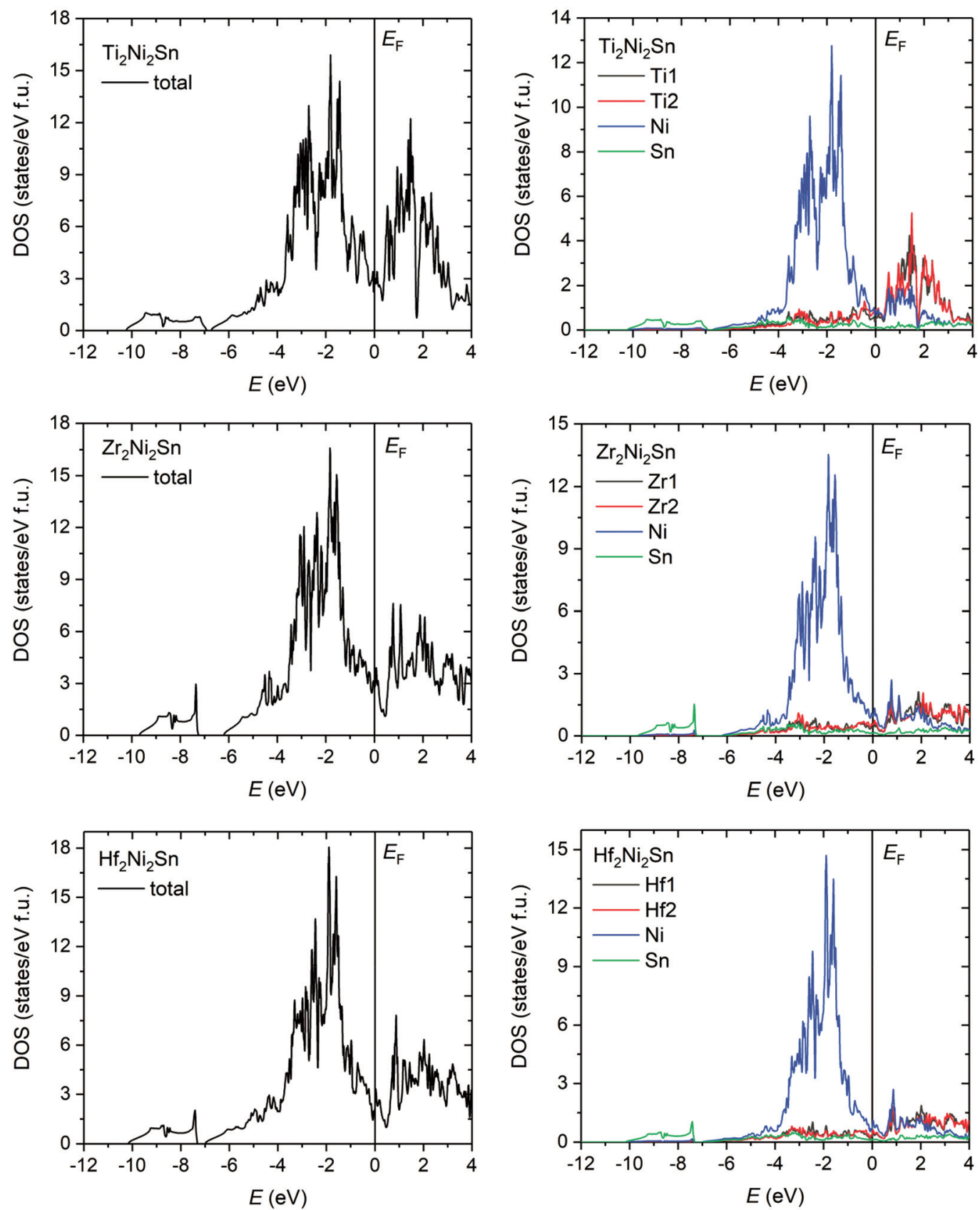

Fig. 10 Distribution of the total and partial density of states of $\mathrm{Ti}_{2} \mathrm{Ni}_{2} \mathrm{Sn}, \mathrm{Zr}_{2} \mathrm{Ni}_{2} \mathrm{Sn}$, and $\mathrm{Hf}_{2} \mathrm{Ni}_{2} \mathrm{Sn}$. The Fermi level $\left(E_{\mathrm{F}}\right)$ is shifted to 0 eV. 
measurements, which is a bulk test. A summary of all elastic moduli from RUS and nanoindentation, as derived for the three compounds $\mathrm{T}_{2+x} \mathrm{Ni}_{2} \mathrm{Sn}_{1-x}$, is presented in Table 2 .

The temperature dependent length change $\Delta \ell / \ell_{0}$ of $\mathrm{Zr}_{2} \mathrm{Ni}_{2} \mathrm{Sn}$ shows a slight anomaly in the range of $45 \mathrm{~K}$, presum- ably referring to small magnetic contributions. To analyze the thermal expansion as a function of temperature, the semiclassical model of Mukherjee et al. ${ }^{39}$ was applied. This treatment takes into account three- and four-phonon interactions, considering the Debye model for acoustic phonons and the
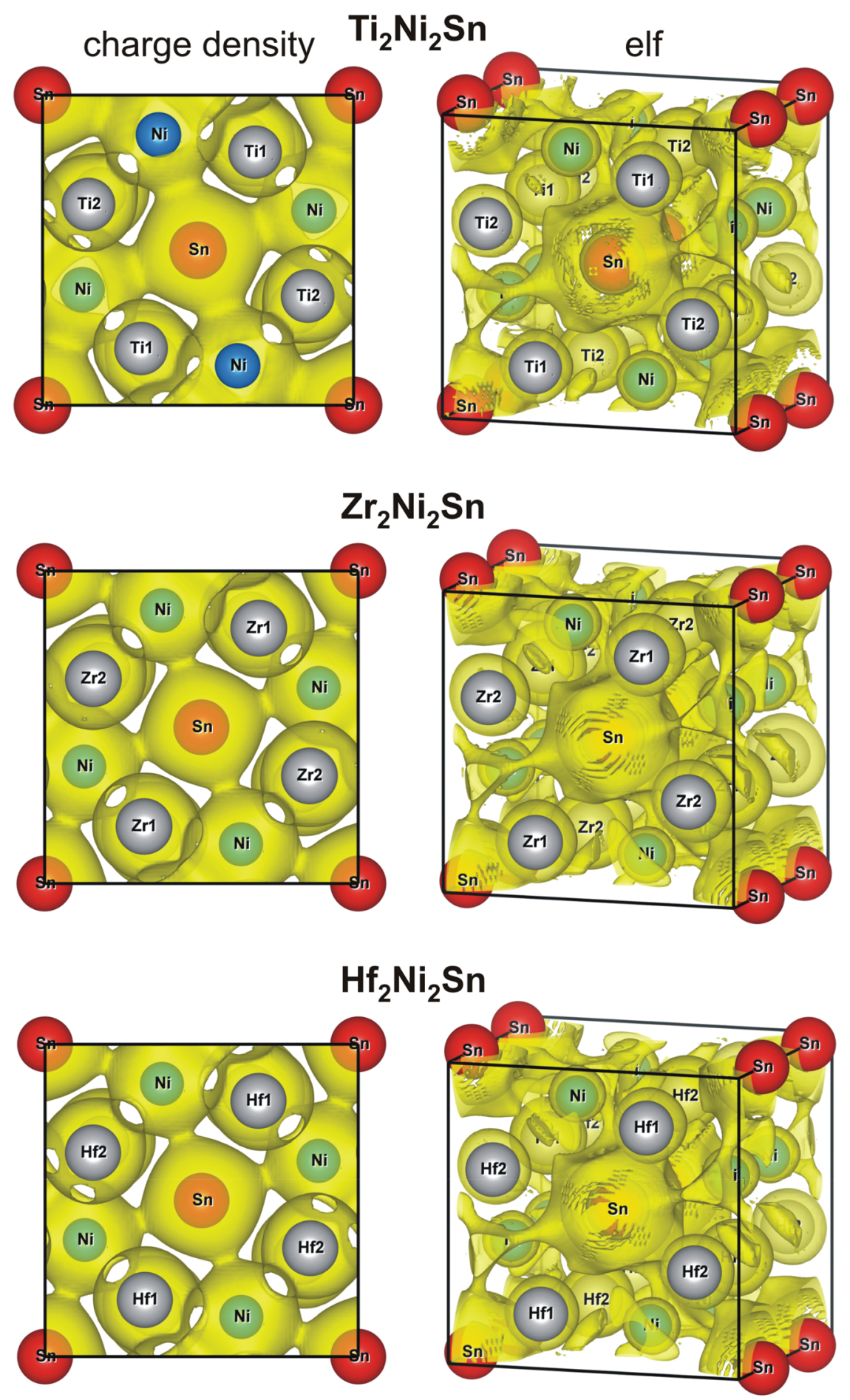

Fig. 11 Iso-surface of the charge density at $0.256 \AA^{-3}$ (left) and the electron localization function at 0.4 (right) of the $\mathrm{Ti}_{2} \mathrm{Ni}_{2} \mathrm{Sn}_{2} \mathrm{Zr}_{2} \mathrm{Ni}_{2} \mathrm{Sn}_{\text {, and }}$ $\mathrm{Hf}_{2} \mathrm{Ni}_{2} \mathrm{Sn}$ compounds. 
Einstein approximation for optical modes. The length change $\Delta \ell \mid \ell\left(T_{0}\right)$ is given by eqn (9)

$$
\begin{aligned}
\frac{\Delta \ell}{\ell\left(T_{0}\right)} & =\frac{\langle x\rangle_{T}-\langle x\rangle_{T_{0}}}{x_{0}} \quad\langle x\rangle_{T}=\frac{\gamma}{2} T^{2}+\frac{3 g}{4 c^{2}}\left[\varepsilon-G \varepsilon^{2}-F \varepsilon^{3}\right] \\
\varepsilon= & \left\{\left(\frac{3}{p}\right) 3 k_{\mathrm{B}} T\left(\frac{T}{\theta_{\mathrm{D}}}\right)^{3} \int_{0}^{\frac{\theta_{\mathrm{D}}}{T}} \frac{z^{3} \mathrm{~d} z}{e^{z}-1}+\left(\frac{p-3}{p}\right) \frac{k_{\mathrm{B}} \theta_{\mathrm{E}}}{e^{\theta_{\mathrm{D}} / T}-1}\right\}, \\
Z=\frac{\hbar \omega}{k_{\mathrm{B}} T} &
\end{aligned}
$$

where $\gamma$ is the electronic contribution to the average lattice displacement, $\theta_{\mathrm{D}}$ is the Debye temperature, $\theta_{\mathrm{E}}$ is the Einstein temperature, and $p$ is the average number of phonon branches actually excited over the temperature range. $G, F, c$, and $g$ are further material dependent constants. The least squares fit (Fig. 8) to the experimental data revealed $\theta_{\mathrm{D}}=331 \mathrm{~K}$ and $\theta_{\mathrm{E}}=$ $128 \mathrm{~K}$, which are in good agreement with those from the specific heat fit.

\subsection{DFT modelling}

For DFT modelling, the fully ordered structures of the $\mathrm{Ti}_{2} \mathrm{Ni}_{2} \mathrm{Sn}, \mathrm{Zr}_{2} \mathrm{Ni}_{2} \mathrm{Sn}$, and $\mathrm{Hf}_{2} \mathrm{Ni}_{2} \mathrm{Sn}$ compounds were taken. At the first stage of calculations, the crystal structure of each compound was optimized by minimizing the total energy of the consecutive variation of the lattice volume, $c / a$ ratio, and fractional atomic coordinates. The resulting lattice parameters and volume are in good agreement with the experimental data (Table 3). The calculated lattice volume of the series (Fig. 9a) significantly increases from $\mathrm{Ti}$ to $\mathrm{Zr}$, and then slightly decreases from $\mathrm{Zr}$ to $\mathrm{Hf}$, which is explained by the difference in their atomic/covalent/ionic radii.

The calculated enthalpy of formation (Table 3 and Fig. 9b) is negative for all studied intermetallics with the lowest value for the $\mathrm{Zr}$ compound. The enthalpies obtained are in good agreement with those reported in ref. 1, 2, 4 and 40 .

The distribution of the total density of states is very similar for all compounds and predicts their metallic type of conductivity (Fig. 10). The corresponding Sommerfeld constants $\gamma_{\mathrm{e}}=$ $\operatorname{DOS}\left(E_{\mathrm{F}}\right) k_{\mathrm{B}} \pi^{2} / 3$ are in good agreement with the experimental data (Fig. 9c). The ratio of the thermal effective mass to the electron mass $\left(m_{\mathrm{th}} / m_{\mathrm{e}}=\gamma_{\exp } / \gamma_{\text {calc. }}\right)$ is within the range of a typical metal and shows a minimum for the $\mathrm{Zr}$ compound (Fig. 9d). The experimentally observed enhancement of the effective electron mass can be referred, besides the electron phonon interaction, primarily to off-stoichiometry effects, as the highest enhancement is observed for the Ti-sample with the largest off-stoichiometry and highest residual resistivity (the opposite holds for the $\mathrm{Zr}$ case).

Even though the Fermi level is positioned on a local maximum for the whole series, there is a well-recognized minimum just above the Fermi level. The valence band is formed mainly by the s- and p-states of Sn and the d-states of $\mathrm{Ni}$, while the states above the Fermi level are contributed mostly by the $\mathrm{Ti} / \mathrm{Zr} / \mathrm{Hf}$ empty d-states. However, a strong overlap of $\mathrm{Sn}$ p-, Ni d-, and partially occupied Ti d-states is observed in the energy region from -5 to $0 \mathrm{eV}$, which is broader than those in the case of the corresponding half- and full-Heusler compounds. Another notable feature is the energy gap between the s-states of Sn (from -10 to $-7 \mathrm{eV}$ ) and the rest of the valence band spectrum, which is significantly larger for the $\mathrm{Zr}$ compound due to the more localized s-states of $\mathrm{Sn}$ in $\mathrm{Zr}_{2} \mathrm{Ni}_{2} \mathrm{Sn}$.

The charge density distribution in Fig. 11 indicates an increase between the closest Ni atoms, which, however, is not well localized. Comparatively smaller saddle points of the charge density are observed between $\mathrm{Ni}$ and $\mathrm{Sn}$ and between $\mathrm{Ni}$ and $\mathrm{Ti} / \mathrm{Zr} / \mathrm{Hf}$ atoms. For the $\mathrm{Ti}_{2} \mathrm{Ni}_{2} \mathrm{Sn}$ compound, the $\mathrm{Ni}-\mathrm{Sn}$ interactions resulted in a more localized charge density, than the rest of the series. Different $\mathrm{Ni}-\mathrm{T}(\mathrm{T}=\mathrm{Ti}, \mathrm{Zr}, \mathrm{Hf})$ distances within the deformed $\mathrm{TNi}_{6}$ trigonal prism resulted in a relatively more localized charge density for the shorter ones. Comparing these distances with the sum of the corresponding atomic and covalent radii ${ }^{32}$ (in nm: $R_{\text {at }}(\mathrm{Ni})=0.1246, R_{\text {cov }}(\mathrm{Ni})=$ $0.115, R_{\mathrm{at}}(\mathrm{Ti})=0.1462, R_{\mathrm{cov}}(\mathrm{Ti})=0.132, R_{\mathrm{at}}(\mathrm{Zr})=0.1602$, $R_{\text {cov }}(\mathrm{Zr})=0.145, R_{\mathrm{at}}(\mathrm{Hf})=0.159, R_{\text {cov }}(\mathrm{Hf})=0.144 ; R_{\mathrm{at}}(\mathrm{Sn})=$ $\left.0.1545 ; R_{\text {cov }}(\mathrm{Sn})=0.1399\right)$, one can see that the shorter $\mathrm{T}-\mathrm{Ni}$ distances are closer to the sum of covalent, and the longer the sum of atomic radii.

More information on the bonding features was obtained through the analysis of the charge density and electron localization function (elf) (Fig. 11, right panels). The iso-surface of elf at the same value for all studied compounds shows a spherical shape for the $\mathrm{Ti} / \mathrm{Zr} / \mathrm{Hf}$ atoms and indicates their ionic character, which corresponds to their unoccupied d-states above the Fermi level. The $\left[\mathrm{Ni}_{2} \mathrm{Sn}\right]^{n-}$ sublattice is characterized by a complex elf distribution with some localizations around the $\mathrm{Ni}$ and $\mathrm{Sn}$ atoms. This is caused by a significantly higher electronegativity of $\mathrm{Ni}$ and $\mathrm{Sn}$ in comparison with $\mathrm{Ti} / \mathrm{Zr} / \mathrm{Hf}$, and as a result stronger electron density attraction toward the $\mathrm{Ni}$ and $\mathrm{Sn}$ atoms.

A comparison of the charge density and elf distribution of the $\mathrm{T}_{2} \mathrm{Ni}_{2} \mathrm{Sn}$ series with the $\mathrm{V}_{2} \mathrm{FeB}_{2}$ compound (partially ordered $\mathrm{U}_{3} \mathrm{Si}_{2}$-type structure ${ }^{41}$ shows that the increase of the charge density between the closest $\mathrm{Ni}$ atoms corresponds to the similar but significantly stronger elf values between the pair of boron atoms in the equivalent crystallographic site.

\section{Conclusion}

Exploiting the knowledge on liquidus surface data and solidification paths for $\mathrm{T}_{2} \mathrm{Ni}_{2} \mathrm{Sn}$ compounds in the ternary systems Ti-Ni-Sn and Zr-Ni-Sn, single-phase materials with slightly non-stoichiometric compositions could be prepared: $\mathrm{Ti}_{2.13} \mathrm{Ni}_{2} \mathrm{Sn}_{0.87}, \mathrm{Zr}_{2.025} \mathrm{Ni}_{2} \mathrm{Sn}_{0.975}$ and $\mathrm{Hf}_{2.055} \mathrm{Ni}_{2} \mathrm{Sn}_{0.945}$. X-ray single crystal analyses and transmission electron microscopy clearly defined the crystal structure of $\mathrm{Ti}_{2+x} \mathrm{Ni}_{2} \mathrm{Sn}_{1-x}, x \sim$ $0.13(1)$, to be isotypic with the $\mathrm{U}_{2} \mathrm{Pt}_{2} \mathrm{Sn}$-type (space group $\mathrm{P4}_{2} / \mathrm{mnm}$, ternary ordered version of the $\mathrm{Zr}_{3} \mathrm{Al}_{2}$-type), i.e. a $(a, 2 c)$-type superstructure of the ordered $\mathrm{U}_{3} \mathrm{Si}_{2}$-type.

The electrical resistivities as a function of temperature measured on the polycrystalline samples of the three com- 
pounds demonstrate metallic-like behavior at lower temperatures, with dominant scattering obviously from static defects provided by off-stoichiometry and grain boundaries.

With a rather low Seebeck coefficient $\left(<15 \mu \mathrm{V} \mathrm{K} \mathrm{K}^{-1}\right)$, only low

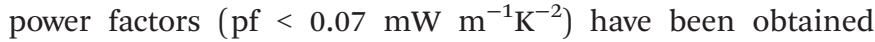
yielding (with an estimated minimum thermal conductivity of $\lambda_{\text {min }} \sim 2.32 \mathrm{~mW} \mathrm{~cm}^{-1} \mathrm{~K}^{-1}$ and a calculated electron part of the thermal conductivity) a thermoelectric figure of merit lower than $\mathrm{ZT} \sim 0.007$ at about $800 \mathrm{~K}$. Whereas the mechanical properties of $\mathrm{T}_{2+x} \mathrm{Ni}_{2} \mathrm{Sn}_{1-x}$ ( $\mathrm{T}=\mathrm{Ti}, \mathrm{Zr}$ or $\mathrm{Hf}$ ) are comparable to $\{\mathrm{Ti}$, $\mathrm{Zr}, \mathrm{Hf}\} \mathrm{NiSn}$ half Heusler alloys, hardness and thermal expansion (measured for $\mathrm{Zr}_{2} \mathrm{Ni}_{2} \mathrm{Sn} \alpha=15.4 \times 10^{-6} \mathrm{~K}^{-1}$ above $180 \mathrm{~K}$ ) are significantly higher than the corresponding values for $\{\mathrm{Ti}$, $\mathrm{Zr}, \mathrm{Hf}\}$ NiSn half Heusler phases. Although the mechanical properties of the $\mathrm{T}_{2} \mathrm{Ni}_{2} \mathrm{Sn}$ compounds are all comparable to those of our advanced thermoelectrics $\{\mathrm{Ti}, \mathrm{Zr}, \mathrm{Hf}\} \mathrm{NiSn}$ with $\mathrm{ZT}$ up to 1.5 (ref. 5 and 6) (for a summary of the mechanical property data of half Heusler alloys, see ref. 20), the ZT values of the $\mathrm{T}_{2} \mathrm{Ni}_{2} \mathrm{Sn}$ phases are negligible. Under the assumption that the influences of electrical and thermal conductivity cancel out, the low Seebeck coefficient of $\mathrm{T}_{2} \mathrm{Ni}_{2} \mathrm{Sn}$ may reduce the overall ZT of a corresponding composite 95\% (Ti,Zr,Hf)NiSn $+5 \%$ $\mathrm{T}_{2} \mathrm{Ni}_{2} \mathrm{Sn}$ already by about $10 \%$. Therefore it is advisable to keep the concentration of these phases in any $\{\mathrm{Ti}, \mathrm{Zr}, \mathrm{Hf}\} \mathrm{NiSn}-$ based thermoelectric composite as low as possible.

The distribution of the DFT-derived total density of states is very similar for all three compounds $\mathrm{T}_{2} \mathrm{Ni}_{2} \mathrm{Sn}$ and confirms their metallic type of conductivity. The corresponding Sommerfeld constants are consistent with the experimental data and the ratio of the thermal effective mass to the electron mass $\left(m_{\mathrm{th}} / m_{\mathrm{e}}=\gamma_{\exp } / \gamma_{\text {calc. }}\right)$ is within the range of typical metals. The valence band is formed mainly by the s and $\mathrm{p}$ states of $\mathrm{Sn}$ and the d-states of $\mathrm{Ni}$, with a strong overlap of $\mathrm{Sn} \mathrm{p,} \mathrm{Ni} \mathrm{d,} \mathrm{and}$ partially occupied $\mathrm{Ti} \mathrm{d}$ states in the region from -5 to $0 \mathrm{eV}$, and is broader than those for the corresponding half- and fullHeusler compounds.

The calculated distributions of the charge density and electron localization function (elf) indicate the ionic character (unoccupied d-states above $E_{\mathrm{F}}$ ) of the Ti/Zr/Hf atoms. The elf of the $\left[\mathrm{Ni}_{2} \mathrm{Sn}\right]^{n-}$ sublattice reflects some localizations around the Ni and Sn atoms with a large somewhat diffuse charge density between the closest $\mathrm{Ni}$ atoms. It is worth noting that the $\mathrm{Ni}-\mathrm{Sn}$ interactions for $\mathrm{Ti}_{2} \mathrm{Ni}_{2} \mathrm{Sn}$ resulted in a more localized charge density than for the rest of the series.

\section{Author contributions}

All authors have contributed equally to the work.

\section{Conflicts of interest}

The authors declare that they have no known competing financial interests or personal relationships that could have appeared to influence the work reported in this paper.

\section{Acknowledgements}

The contributions of Dr M. Gürth, Dr P. Sauerschnig and particularly of Daniel Langerreiter in his bachelor work at the early stages of this manuscript and the contributions of Dr Herbert Müller (thermal expansion) and Dr Stephan Puchegger (RUS) are cordially acknowledged. The authors thank U. Nitzsche for technical assistance in running DFT calculations on the ITF/IFW computer cluster. Dr V. Romaka is thankful for the support from the Austrian Federal Ministry of Science and Research (BMWF) within the Ernst Mach fellowship program and the German Federal Ministry of Education and Research (BMBF) within the UKRATOP project (01DK18002). This research was supported by MEYS, Czech Republic via the bilateral Mobility project 8J21AT015 co-sponsored by Austrian WTZ-CZ16/2021. This paper is dedicated to Dr. Helmut Holleck, in memoriam.

\section{References}

1 M. Gürth, A. Grytsiv, J. Vrestal, V. V. Romaka, G. Giester, E. Bauer and P. Rogl, On the constitution and thermodynamic modelling of the system Ti-Ni-Sn, RSC Adv., 2015, 112(5), 92270-92291.

2 P. Sauerschnig, A. Grytsiv, J. Vrestal, V. V. Romaka, B. Smetana, G. Giester, E. Bauer and P. Rogl, On the constitution and thermodynamic modelling of the system $\mathrm{Zr}-\mathrm{Ni}$ Sn, J. Alloys Compd., 2018, 742, 1058-1082.

3 Yu. V. Stadnyk and L. P. Romaka, Phase equilibria in the Hf-Ni-Sn ternary system and crystal structure of the Hf2Ni2Sn compound, J. Alloys Compd., 2001, 316, 169171.

4 A. Berche, J. C. Tédenac and P. Jund, Phase diagram and enthalpy of formation of Hf-Ni-Sn, Comput. Mater. Sci., 2016, 125, 271-277.

5 M. Gürth, G. Rogl, V. V. Romaka, A. Grytsiv, E. Bauer and P. Rogl, Thermoelectric high ZT half-Heusler alloys $\mathrm{Ti}_{1-x-y} \mathrm{Zr}_{x} \mathrm{Hf}_{y} \mathrm{NiSn}$, Acta Mater., 2016, 104, 210-222.

6 G. Rogl, P. Sauerschnig, Z. Rykavets, V. V. Romaka, P. Heinrich, B. Hinterleitner, A. Grytsiv, E. Bauer and P. Rogl, (V,Nb)-doped half Heusler alloys based on $\{\mathrm{Ti}, \mathrm{Zr}$, Hf\}NiSn with high ZT, Acta Mater., 2017, 131, 336-348.

7 R. Pöttgen and R. Dronskovsky, Structure and Properties of $\mathrm{Zr}_{2} \mathrm{Ni}_{2} \mathrm{In}$ and $\mathrm{Zr}_{2} \mathrm{Ni}_{2} \mathrm{Sn}$, J. Solid State Chem., 1997, 128, 289294.

8 M. F. Zumdick, R. Pöttgen, R. Müllmann, B. D. Mosel, G. Kotzyba and B. Künnen, Synthesis, crystal structure, and properties of $\mathrm{Hf}_{2} \mathrm{Ni}_{2} \mathrm{In}, \mathrm{Hf}_{2} \mathrm{Ni}_{2} \mathrm{Sn}, \mathrm{Hf}_{2} \mathrm{Cu}_{2} \mathrm{In}$ and $\mathrm{Hf}_{2} \mathrm{Pd}_{2} \mathrm{In}$ with ordered $\mathrm{Zr}_{3} \mathrm{Al}_{2}$ type structure, Z. Anorg. Allg. Chem., 1998, 624, 251-256.

9 V. V. Romaka, P. Rogl, L. Romaka, Yu. Stadnyk, N. Melnychenko, A. Grytsiv, M. Falmbigl and N. Skryabina, Phase equilibria, formation, crystal and electronic structure of ternary compounds in $\mathrm{Ti}-\mathrm{Ni}-\mathrm{Sn}$ and $\mathrm{Ti}-\mathrm{Ni}-\mathrm{Sb}$ ternary systems, J. Solid State Chem., 2013, 197, 103-112. 
10 R. Gaillac and F. X. Coudert, ELATE, Elastic terms analysis, J. Phys.: Condens. Matter, 2012, 8(6), 275201.

11 INCA Energy-300 and INCA Wave 700, Oxford Instruments Analytical Ltd, UK, 2000.

12 J. Rodriguez-Carvajal, Recent developments of the program FULlPROF, Phys. B, 1993, 55, 192. See also: T. Roisnel and J. Rodriguez-Carvajal, Mater. Sci. Forum, 2001, 118, 378381.

13 W. Wacha, Diploma thesis, Vienna University of Technology, Vienna, Austria, 1989.

14 Bruker Advanced X-ray solutions. APEX2 User Manual. Version 1.22.2004, Bruker AXS Inc. For APEXII, SAINT and SADABS see 2008, Bruker Analytical X-ray Instruments, Inc., Madison, Wisconsin, USA.

15 G. M. Sheldrick, SHELX - Program for Crystal Structure Refinement, Acta Crystallogr., Sect. A: Found. Crystallogr, 2008, 64, 112-122; Windows version OSCAIL byP. McArdle, K. Gilligan, D. Cunningham, R. Dark and M. Mahon, CrystEngComm, 2004, 6, 303-309.

16 E. Parthé, L. Gelato, B. Chabot, M. Penzo, K. Censual and R. Gladyshevskii, TYPIX - Standardized Data and Crystal Chemical Characterization of Inorganic Structure Types, Springer-Verlag, Berlin, Heidelberg, 1994, vol. 1, p. 186. See alsoL. M. Gelato and E. Parthé, STRUCTURE TIDY - a computer program to standardize crystal structure data, J. Appl. Crystallogr., 1987, 20, 139-143.

17 A. Migliori, J. Sarrao, W. M. Visscher, T. M. Bell, M. Lei, Z. Fisk and R. G. Leisure, Resonant ultrasound spectroscopic techniques for measurement of the elastic moduli of solids, Phys. B, 1993, 183, 1-24.

18 L. Zhang, G. Rogl, A. Grytsiv, S. Puchegger, J. Koppensteiner, F. Spieckermann, H. Kabelka, M. Reinecker, P. Rogl, W. Schranz, M. Zehetbauer and M. A. Carpenter, Mechanical properties of filled antimonide skutterudites, Mater. Sci. Eng., B, 2010, 170, 26-31.

19 G. Rogl and P. Rogl, Mechanical properties of skutterudites, Sci. Adv. Mater., 2011, 3, 1-22.

20 G. Rogl, A. Grytsiv, M. Gürth, A. Tavassoli, C. Ebner, A. Wünschek, S. Puchegger, V. Soprunyuk, W. Schranz, E. Bauer, H. Müller, M. Zehetbauer and P. Rogl, Mechanical properties of half-Heusler alloys, Acta Mater., 2016, 107, 178-195.

21 O. L. Anderson, A simplified method for calculating the Debye temperature from elastic constants, J. Phys. Chem. Solids, 1963, 24, 909.

22 E. Schreiber, O. L. Anderson and N. Soga, Elastic Constants and their Measurements, Mc Graw Hill, New York, 1973.

23 M. Rotter, H. Müller, E. Gratz, M. Dörr and M. Löwenhaupt, A miniature capacitance dilatometer for thermal expansion and magnetostriction, Rev. Sci. Instrum., 1998, 69, 2742-2746.

24 G. Brändli and R. Griessen, Two capacitance dilatometers, Cryogenics, 1973, 13, 299-302.
25 J. Genossar and M. Steinitz, A tilted plate capacitance displacement sensor, Rev. Sci. Instrum., 1990, 61, 2469-2470.

26 Elk Program package; http://elk.sourceforge.net/.

27 J. P. Perdew, K. Burke and M. Ernzerhof, Generalized gradient approximation made simple, Phys. Rev. Lett., 1996, 77(18), 3865-3868.

28 P. Vinet, J. H. Rose and J. S. Ferrante Jr., Universal features of the equation of state of solids, J. Phys.: Condens. Matter, 1989, 1, 1941-1964.

29 K. Momma and F. Izumi, VESTA 3 for three-dimensional visualization of crystal, volumetric and morphology data, J. Appl. Crystallogr., 2011, 44, 1272-1276.

30 P. Villars and K. Censual, Pearson's Crystal Data: Crystal Structure Database for Inorganic Compounds, ASM International, Materials Park, Ohio, USA, Release 2019/20.

31 V. I. Zaremba, L. D. Gulai, Ya. M. Kalychak and L. G. Akselrud, Crystal structure of compounds with $\mathrm{Mo}_{2} \mathrm{FeB}_{2}$-type structure in $\{\mathrm{Zr}, \mathrm{Hf}\}-\{\mathrm{Co}, \mathrm{Ni}, \mathrm{Cu}\}$-In systems, Kristallografiya, 1995, 40(2), 369.

32 W. B. Pearson, The Crystal Chemistry and Physics of Metals and Alloys, Wiley-Interscience, New York, USA, 1972. The 12-coordinated metallic radii in Table 4-4 of this book have been taken from: E. Teatum, K. Gschneidner and J. Waber, Report LA-2345, US Department of Commerce, Washington, D.C., USA, 1960.

33 P. Stadelmann, JEMS: Java Electron Microscopy Software, available from: http://www.jems-swiss.ch/, 2021.

34 P. A. Stadelmann, EMS - a software package for electron diffraction analysis and HREM image simulation in materials science, Ultramicroscopy, 1987, 21(2), 131-145.

35 M. Wang, H. S. Liu, G. M. Cai and Z. P. Jin, Measurement of phase equilibria in Ti-Ni-Sn system, Trans. Nonferrous Met. Soc. China, 2018, 28, 819-828.

36 Y. V. Stadnyk and R. V. Skolozdra, $770 \mathrm{~K}$ isothermal section of the Ti-Ni-Sn system, Inorg. Mater., 1991, 27(10), 1884-1885.

37 D. G. Cahill and R. O. Pohl, Heat flow and lattice vibrations in glasses, Solid State Commun., 1989, 70(10), 927-930.

38 W. C. Oliver and G. M. Pharr, An improved technique for determining hardness and elastic modulus using load and displacement sensing indentation experiments, J. Mater. Res., 1992, 7, 1564-1583.

39 G. D. Mukherjee, C. Bansal and A. Chatterjee, Thermal expansion study of ordered and disordered $\mathrm{Fe}_{3} \mathrm{Al}$ : $\mathrm{An}$ effective approach for the determination of vibrational entropy, Phys. Rev. Lett., 1996, 76(11), 1876-1879.

40 A. Berche, J. C. Tédenac and P. Jund, Phase stability of nickel and zirconium stannides, J. Phys. Chem. Solids, 2017, 103, 40-48.

41 P. Rogl, V. Romaka, J. Bursik, H. Michor, M. Reissner, G. Giester and V. Homolova, Structure and properties of a novel boride $\left(\mathrm{V}_{0.92} \mathrm{Fe}_{0.08}\right)_{2} \mathrm{FeB}_{2}$ with partially ordered $\mathrm{U}_{3} \mathrm{Si}_{2}$ type, J. Alloys Compd., 2018, 746, 638-647, DOI: 10.1016/j. jallcom.2018.02.323. 